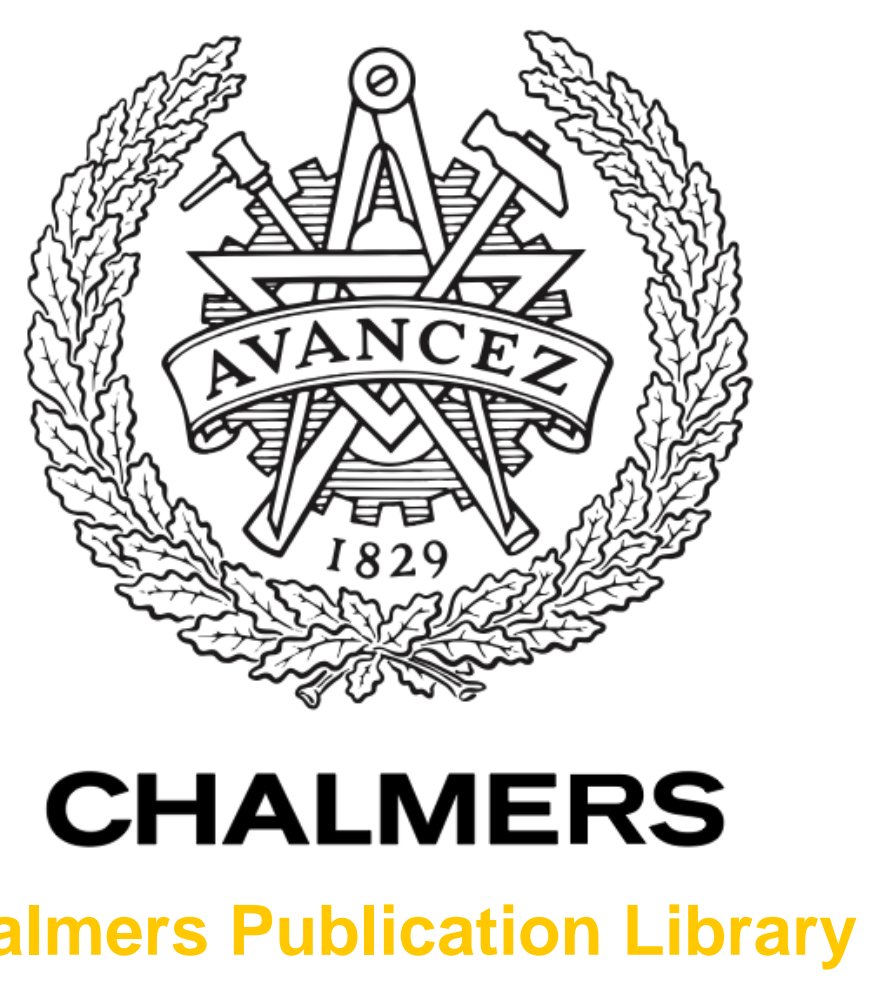

Chalmers Publication Library

\title{
A multi-level modelling and evaluation of thermal performance of phase change materials in buildings
}

This document has been downloaded from Chalmers Publication Library (CPL). It is the author's version of a work that was accepted for publication in:

Journal of Building Performance Simulation, Taylor \& Francis (ISSN: 1940-1493)

Citation for the published paper:

Sasic Kalagasidis, A. (2013) "A multi-level modelling and evaluation of thermal performance of phase change materials in buildings". Journal of Building Performance

Simulation, Taylor \& Francis, vol. 7(4), pp. 289-308.

http://dx.doi.org/10.1080/19401493.2013.764547

Downloaded from: http://publications.lib.chalmers.se/publication/182919

Notice: Changes introduced as a result of publishing processes such as copy-editing and formatting may not be reflected in this document. For a definitive version of this work, please refer to the published source. Please note that access to the published version might require a subscription.

Chalmers Publication Library (CPL) offers the possibility of retrieving research publications produced at Chalmers University of Technology. It covers all types of publications: articles, dissertations, licentiate theses, masters theses, conference papers, reports etc. Since 2006 it is the official tool for Chalmers official publication statistics. To ensure that Chalmers research results are disseminated as widely as possible, an Open Access Policy has been adopted.

The CPL service is administrated and maintained by Chalmers Library. 


\title{
A multi-level modelling and evaluation of thermal performance of phase change materials in buildings
}

\author{
Angela Sasic Kalagasidis \\ Department of Civil and Environmental Engineering \\ Chalmers University of Technology, Gothenburg, Sweden \\ angela.sasic@chalmers.se
}

\begin{abstract}
Integration of phase change materials (PCMs) in building envelopes is a way to enhance heat storage capacity of buildings and thereby to rationalize the use of energy for heating and cooling of buildings. This work presents a numerical model of a building envelope with PCMs, verifications of the model according to a normative benchmark and a tentative case study that exemplifies the effects of such a building envelope on the thermal performance of a whole building. All these simulations have been carried out using a modular environment of the International Building Physics Toolbox (IBPT) in Simulink ${ }^{\circledR}$, for which validation results are also provided. As for the effects of PCMs in buildings, it is concluded that they are rather case sensitive; in the tentative case study, the annual savings of total energy for heating and cooling vary between $5 \%$ and $21 \%$, depending mainly on the thermal comfort and the placement of PCM in the building envelope.
\end{abstract}

Key words: PCM, IBPT library, Simulink ${ }^{\circledR}$, modular programmes, whole buildings, thermal storage

\section{Introduction}

One of the great challenges of the modern world is the reduction of energy use in buildings to the levels required for attaining sustainable development. Energy efficiency measures recommended for this purpose aim also at providing high-quality and affordable housing. Modern building industry aspires to bring together societal expectations and those of the occupants by constructing energy efficient, durable and well performing buildings. Although significant results can be accomplished with available materials and techniques, more strict energy regulations complicate the building process. As an example, a better insulation of 
buildings is recognized as an energy efficiency measure. Extra insulation increases the weight and thickness of the building envelope and requires new solutions for the supporting structure and connections. The reduced daylight and living area are some of the architectural difficulties that are created by thick walls. Besides, as parts of the building envelope become colder, moisture durability issues can come into view. With this in mind, a preferable building envelope is to be well insulated, durable, easy to assemble, slim and reasonably priced.

New solutions for well insulated building envelopes largely depend on the progress in the fields of high performance thermal insulation and techniques for the control of flow of heat through the building envelope. Building simulation tools should be seen here as valuable means for design, verification and optimization of novel components, as they can consider the performance of a component in respect to realistic working conditions (created by the local climate, building tradition, building type and use). It is thus essential that novel building envelope components are adequately presented in building simulations.

High performance thermal insulation, whose thermal properties are fairly constant for the range of temperatures found in buildings, can be easily presented in building energy simulation tools. Vacuum panels and aerogel felts are some of the representatives. In contrast, thermally activated materials and components represent challenging modelling tasks. The reason for the latter observation is that, in such materials and components, the transfer and storage of heat are governed by fluids (water or air) flowing thorough a system of embedded pipes, channels and cavities (floor heating, ventilated facades), directly through the insulation material (dynamic walls), or by phase change materials (PCMs). The thermal response of activated components changes in a complex way with the thermal load from the environment and it may include phase transition states of matter. Assessment of activated components requires energy and mass balance computational routines that are adapted to combined conduction-convection and phase-transition problems. Such computational routines are rather 
costly in terms of modelling efforts and computational time, and thus not always readily available in building simulation programmes. A high interest for the application of a particular component in buildings may trigger the development of building simulation tools, as it was the case with PCMs. Nowadays the models of PCMs are available in many of the conventional building simulation tools such as TRNSYS, ESP-r, EnergyPlus and WUFI 5.

As for the modelling efforts, different users have diverse preferences to the structure of building simulation programmes. Ready-to-use simulation programmes are very much welcome in both design and research practice because they require the least effort from the side of a user. Such programmes are characterized by a standardized set of input data, which is adapted to the calculation options provided in the programme. Short computer run-time is another much appreciated feature of these programmes because it facilitates evaluation of a large number of design options in often time-pressed process of building design. A major drawback of these programmes is that the user cannot easily extend the number of simulation options in the programme, because, for example, he/she is not given the access to the source code, as it is provided in ESP-r, EnergyPlus and TRNSYS, or due to various difficulties related to direct coding. Modular tools, for instance TRNSYS, and modelling platforms with development options, such as Matlab/Simulink ${ }^{\circledR}$ and Comsol ${ }^{\circledR}$, are thus more convenient for research and development (R\&D) projects since they offer possibility to model and solve numerical problems as 'the need appears'. Through a user friendly interface, which excludes or minimizes the need for direct coding, these platforms facilitate a fast development and an easy exchange of the models. Such modelling possibilities were recognized in Simulink ${ }^{\circledR}$, the graphical modelling environment of Matlab, and then incorporated in the International Building Physics Toolbox (IBPT), (Sasic Kalagasidis et al. 2007). However, many of these benefits are provided on the expense of simulation time. 
The IBPT was established in 2002 on the initiative of two research groups from Chalmers University of Technology in Sweden and the Danish Technical University, for the purpose of developing simulation tools for building physics applications. The IBPT was conceptualized as a 'universal' building simulation tool, i.e. as a tool that allows presentation of buildings and building components on different levels of detail. From the start, the IBPT was placed on the Internet as an open source for everyone who could benefit from it. The open access to the IBPT library, its modular structure and a set of established rules on how to connect the models have been of crucial importance for the development of sub-libraries and their applications on various research and building design problems. There are examples of models and applications for thermal problems only (Ståhl 2009), coupled thermal, air and moisture problems (Hagentoft et al. 2004, Moussavi Nik et al. 2012, Woloszyn and Rode 2008), and for the analysis of volatile organic compounds alone (Karlsson et al. 2005), or coupled to the hygrothermal processes (Sasic Kalagasidis et al. 2005). As for the thermally activated building components, the examples can be found on dynamic thermal insulation (Sasic Kalagasidis 2004) and embedded thermal systems (Karlsson 2010).This work presents the IBPT- based models for the design and evaluation of building envelopes with PCMs.

Although the above mentioned libraries are rather unique, they were all developed from the basic IBPT modelling kit and by respecting the initially established modelling principles. The aim of the work is thus to show the significance of a modular structure of a simulation toolbox such as the IBPT, for the design and evaluation of activated building components, by using PCM as an example. As the IBPT mirrors the modelling environment of Matlab/Simulink ${ }^{\circledR}$, this work at the same time presents and discusses the benefits of using such modelling platforms for R\&D projects. 


\section{Phase change materials}

Storage of thermal energy can be accomplished either by using sensible heat storage or latent heat storage. Heavyweight building materials, such as stone, brick and soil have been used for centuries to passively store/release the heat from the Sun and other heat sources in indoor and outdoor environments. A substantially smaller volume of a material is required to store the same amount of energy when latent storage systems are used, such as PCMs. Integration of PCMs into building envelopes is a way to enhance the storage capacity of buildings and thus to rationalize the use of energy sources.

\subsection{Overview of research on PCM}

Research on PCM-based building materials has been reported since the late 1970s (Kuznik et al. 2011). A majority of the investigations conducted in the meantime were focused on physical integration of PCM with a core material and experimental evaluation of their thermophysical properties. Relevant PCM for the usage in rooms are paraffin, fatty acids, salt hydrates and their eutectic mixtures (Volker et al. 2008) because they show good chemical stability, high latent heat and very limited super cooling (Evola et al. 2011). The simplest method to integrate PCM in buildings is a direct impregnation in gypsum, concrete or other porous materials (Evola et al. 2011).At present, this method is nearly left behind due to a poor thermal performance of such products, caused by a low share (weight \%) of PCM (Sadineni et al. 2011). Besides, leakages and corrosion of the reinforcement (Cabeza et al. 2007) and difficulties of affixing paint or other wall finishes (Evers et al. 2010) are reported as negative side effects. Micro-encapsulation of PCM is much more effective as it allows a higher PCM weight ratio, ranging from about $30 \%$ in gypsum (Cabeza et al. 2007, Tyagi et al. 2011) to 60 \% in polymeric structures (Kuznik et al. 2008b). In the latter, a PCM is enclosed in microscopic polymer capsules that form a powder; the powder is then included in a container 
made of plastic or aluminium, or blended with a high density polyethylene / wood flour composite (matrix) by compression moulding method. Such a product is generally sold as a panel, easy to be handled with and installed (Evola et al. 2011). Pouches filled with salt mixtures are found appropriate for heat exchangers in ventilation systems (Hed 2003), but significant leakages are noted when similar products are applied in building envelopes (Kosny et al. 2007). There were also attempts to enhance loose-fill cellulose insulation with PCM, (Kosny et al. 2007, Evers et al. 2010). The cited studies also included experimental evaluations of thermo-physical properties of respective PCM in laboratory environments. In general, there are a large number of different and handy PCM-based boards and products on the market (see for example Streicher et al. 2005).

Large scale experimental investigations (in test huts or test rooms) have been primarily focused on showing the capability of PCM to dampen the fluctuations of indoor temperature (Cao et al. 2010, Cabeza et al. 2007, Castell et al. 2010, Cerón et al. 2011, Dutil et al. 2011 and Kosny et al. 2007 and just a few on the capability of reducing peak heat fluxes and surface temperatures, (Evers et al. 2010, Kuznik et al. 2008a, Schossiga et al. 2005, Voelker et al. 2008). While improvements have been observed in all the studies, these findings are of limited applicability for practice since they refer to the conditions that are out of the comfort range in buildings, i.e. from $28{ }^{\circ} \mathrm{C}$ and above, or without common disturbances coming from users, appliances or HVAC equipment.

The thermal performance of PCM is affected by a large number of parameters in indoor and outdoor environments, as well as by the position in the building envelope. These parameters may superpose or counteract when they act combined, making it difficult to generalize findings from experimental studies. Building simulation tools are of great help here as the effect of each influential parameter can be virtually isolated and assessed in numerical experiments. Up to recently, the majority of numerical investigations that addressed possible 
effects of PCMs on energy demand in buildings regarded simplified operating conditions, such as test chambers, non-occupied rooms or pre-defined boundary conditions (Cao et al. 2010, Cabeza et al. 2007, Castell et al. 2010, Cerón et al. 2011, Dutil et al. 2011, Ibáñezet al. 2005, Kosny et al. 2007, Silva et al. 2012, Sá et al. 2012). This trend is changing in favour of the studies that consider effects of PCMs in buildings in use, (Heim and Clarke 2004, Lin et al. 2005, Evola et al. 2011, Shrestha et al. 201, Kosny et al. 2012). In contrast to majority of PCM studies, the numerical simulations presented in this work show that PCM-based products do not have to be directly exposed to the building interior in order to achieve maximum effects. Similar findings have been reported from the experiments performed by Kosny et al.(2007).This opens new application possibilities, particularly in relation to fire safety of the building envelope (Kontogeorgos and Founti 2010). However, as pointed by Kuznik et al.(2011) and Pasupathy et al.(2008), further investigations are needed to consistently assess the use of PCMs in order to avoid non-conclusive results.

Building and construction currently forms the largest application market for PCMs due to the globally increasing demand for cooling of buildings, which has arisen due to the shift from heavy thermal mass design to lightweight architecture but also because of better insulation of buildings (Markets and markets 2012).

\subsection{Thermodynamics of PCMs}

The PCM in building materials is usually in solid phase. At higher heat loads from the environment, the PCM begins to melt if its melting point is reached. During melting, the PCM continues to absorb the excess heat at approximately constant temperature. When the whole amount of the PCM is melted, its temperature starts to increase. Similarly, when the heat load is reduced, the PCM cools down until the solidification starts. This time the energy is released to the environment. Depending on the composition of a PCM, the phase change process may happen at a constant temperature or within a temperature range. For the former, the enthalpy 
line takes the form A, as shown inFigure 1, and for the latter, the form B. An apparent volumetric heat capacity of the PCM of type B can be found as the first derivative of enthalpy $H_{P C M}\left(\mathrm{~J} / \mathrm{m}^{3}\right)$ over temperature $T$

$$
C_{P C M}(T)=\frac{d H_{P C M}}{d T}
$$

In this, the enthalpy is defined per total volume of PCM, $V_{P C M}\left(\mathrm{~m}^{3}\right)$.
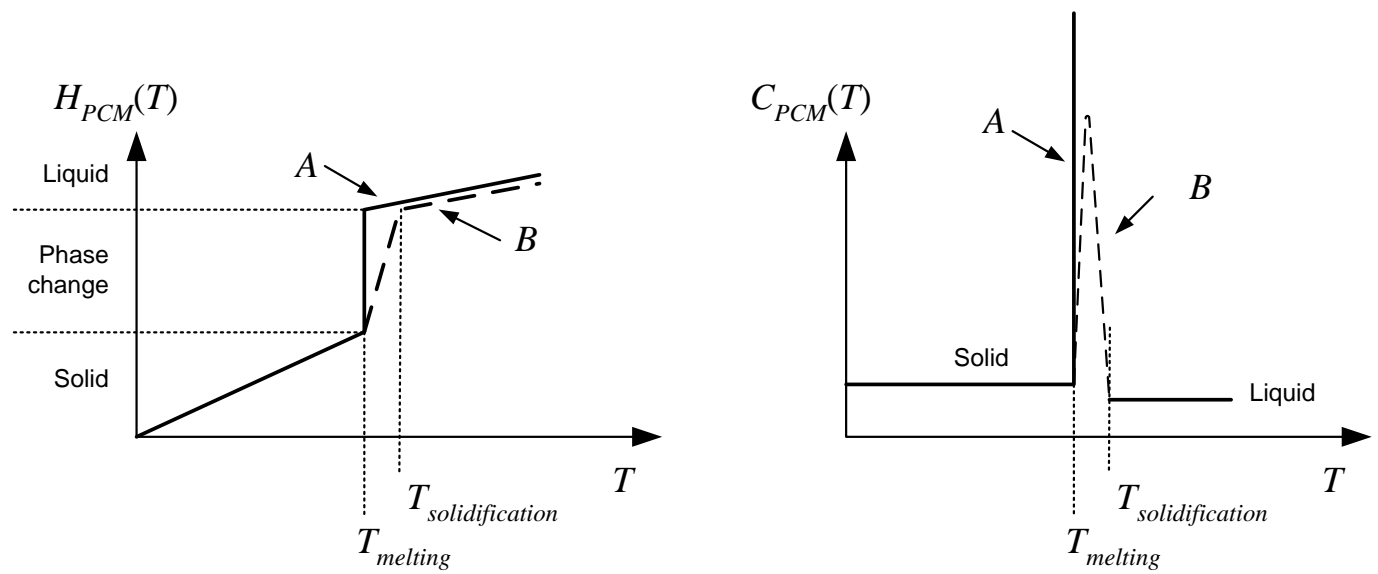

Figure 1 Enthalpy lines and volumetric heat capacities of different types of PCMs

The enthalpy form A requires a two-phase modelling approach in order to get a correct mass balance between the solid and the liquid phase. The overall volume of the PCM is composed of a solid part, $V_{P C M, s}$ and a liquid part, $V_{P C M, l}$

$V_{P C M}=V_{P C M, S}+V_{P C M, l}$

while its total enthalpy reads

$$
H_{P C M} \cdot V_{P C M}=\underbrace{\rho_{P C M, s} \cdot C_{p, P C M, s} \cdot V_{P C M, s} \cdot T}_{\text {solid phase, sensitive }}+\underbrace{\rho_{P C M, l} \cdot C_{p, P C M} \cdot V_{P C M, l} T}_{\text {liquid phase, sensitive }}+\underbrace{\rho_{P C M, l} \cdot V_{P C M, l} \cdot r}_{\text {liquid phase, latent }}
$$

where $c_{p, P C M, s}$ and $c_{p, P C M, l}$ are specific heat capacities, $\rho_{P C M, s}$ and $\rho_{P C M, l}$ are densities of the solid and the liquid phase respectively, $(\mathrm{J} / \mathrm{kgK})$, and $r(\mathrm{~J} / \mathrm{kg})$ is the latent heat of melting/solidification. 
In the pure solid or pure liquid phase regions, the change of enthalpy is proportional to the change of temperature

$$
d H_{P C M}=\mid \begin{aligned}
& \rho_{P C M, s} \cdot c_{p, P C M, s} \cdot d T=C_{P C M, s} \cdot d T \quad \text { if } \quad T<T_{\text {melting }} \\
& \rho_{P C M, l} \cdot c_{p, P C M, l} \cdot d T=C_{P C M, l} \cdot d T \quad \text { if } \quad T>T_{\text {melting }}
\end{aligned}
$$

And the volumetric heat capacities of the solid and liquid phases can be defined. In the phase transition region, i.e. when $T=T_{\text {melting, }}$, the volumes of the solid and the liquid phases change, while the temperature remains constant

$$
d H_{P C M} \cdot V_{P C M}=\left(C_{P C M, s} \cdot d V_{P C M, s}+C_{P C M, l} \cdot d V_{P C M, l}\right) \cdot T+C_{P C M, l} \cdot d V_{P C M, l} \cdot r
$$

Assuming a constant total volume of PCM, the volumes of the solid and the liquid phase change dependently of each other

$$
d V_{P C M}=d V_{P C M, s}+d V_{P C M, l}=0 \quad \Rightarrow \quad d V_{P C M, s}=-d V_{P C M, l}
$$

By letting $\chi$ to denote the volumetric share of the liquid phase in the mixture

$$
\chi=\frac{V_{P C M, l}}{V_{P C M}}, \quad(1-\chi)=\frac{V_{P C M, s}}{V_{P C M}}
$$

The change of enthalpy from equation (5) can be expressed as

$$
d H_{P C M}=-C_{P C M, s} \cdot T \cdot d \chi+\left(C_{P C M, l} \cdot T+r\right) \cdot d \chi
$$

The share of the liquid phase changes with the heat load from the environment. Therefore, the mass balance equation (6) should be complemented with an appropriate energy balance equation.

From the modelling point of view, the PCM of type B are easier. The apparent volumetric heat capacity, as defined by equation (1), can be directly incorporated into the model, as any another property that is temperature dependent. A rather complicated routine is required for the PCM of type A in order to keep track of the direction of the process, as well as of the amounts of each phase. Both modelling approaches are further illustrated in section 3.1. 


\section{Modelling of the PCM in the IBPT environment}

One of the major benefits of using Simulink environment for the IBPT is the possibility of graphical modelling, where different mathematical operations are organized in block diagrams rather than in command lines. By combining basic block diagrams of Simulink into more complex and specific ones, such as those of the IBPT, and then further on into functional schemes, a fast model development is achieved. Furthermore, Simulink has built-in state-ofthe-art ordinary differential equation (ODE) solvers, which are automatically configured at run-time. Therefore, a developer can focus on implementation of a physical model, without too much concern on discretization issues and ODE solvers.

As mentioned above, the IBPT is a model library which means that it contains 'originals' of block diagrams. A model which is composed of the IBPT blocks contains thus instances, i.e. the linked copies of the objects in the library. A drag and drop action is used to move objects from the library into a model, during which Simulink automatically establishes links between the original blocks and their instances. These links serve to propagate changes made on original blocks in the library to their instances elsewhere in the models. The opposite is also possible, i.e. to make changes on instances in the model and to propagate them to their original object in the library. Links are automatically updated at the start of a simulation, or by demand of a user if so specified. It is thus essential to plan and organize the content of the library so that it can facilitate fast development work.

As the IBPT is adapted to building physics applications, it contains models ranging from a single building material to the whole buildings with adjoining service systems. Accordingly, the modelling with the IBPT blocks can be performed on different levels, as depicted in Figure 2. At Level 1, the transfer and storage properties (thermal, moisture, air, etc.) of a material can be specified. The outputs of these models are the states and transfer coefficients at given working conditions. At Level 2, the performance of a component in a 
building envelope is studied, in respect to prescribed boundary conditions. The building envelope components are usually composed of a single or several materials and they might include building services such as floor heating system. Typical outputs of the component blocks are the states and flows at the interfaces between the layers of the materials or between the material and surrounding air. Finally, the response of internal air zones and the performance of a whole building are studied at Level 3. In contrast to Level 2, the boundary conditions at the interior surfaces are this time calculated by taking into account the performance of each component of the building envelope, internal gains and weather conditions. The content and structure of input and output signals of the blocks on Level 3 is pre-defined and fixed in order to facilitate the exchangeability of the blocks even when they are developed by different users.

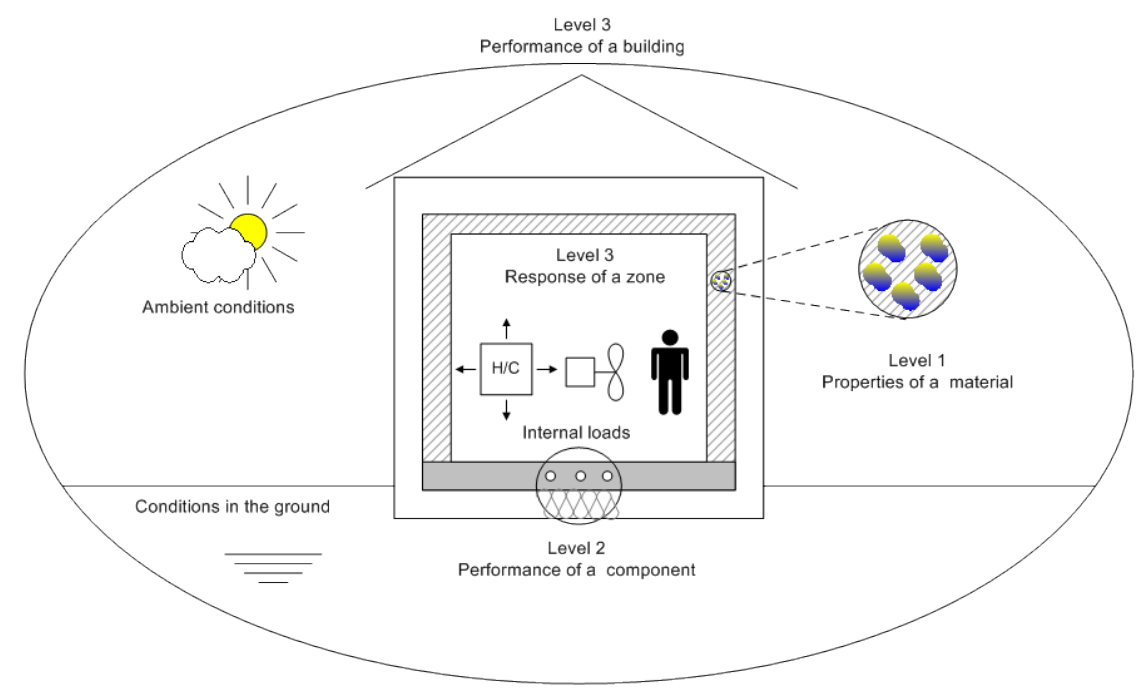

Figure 2 Different levels of modelling with the blocks from the IBPT library.

The presented organization of the IBPT library has not changed over time, i.e. it has been shown optimal for the stated modelling purposes. Further details on the exact content of the library and the signal structure, so called IBPT interface, can be found on the website of 
the IBPT (www.ibpt.org). This work provides an example on how this organization of the library facilitates the introduction of new models, such as materials with PCMs.

\subsection{Level 1 - modelling of thermal properties of PCM}

The IBPT models for heat transfer analyses are termed H-Tools; they support transient onedimensional heat transfer through a multi-layered wall by using a control volume numerical method. With this technique, each layer of the material is divided into sub-layers of the same area but with arbitrary thicknesses. Each sub-layer represents then a control volume where energy balance equations are established.

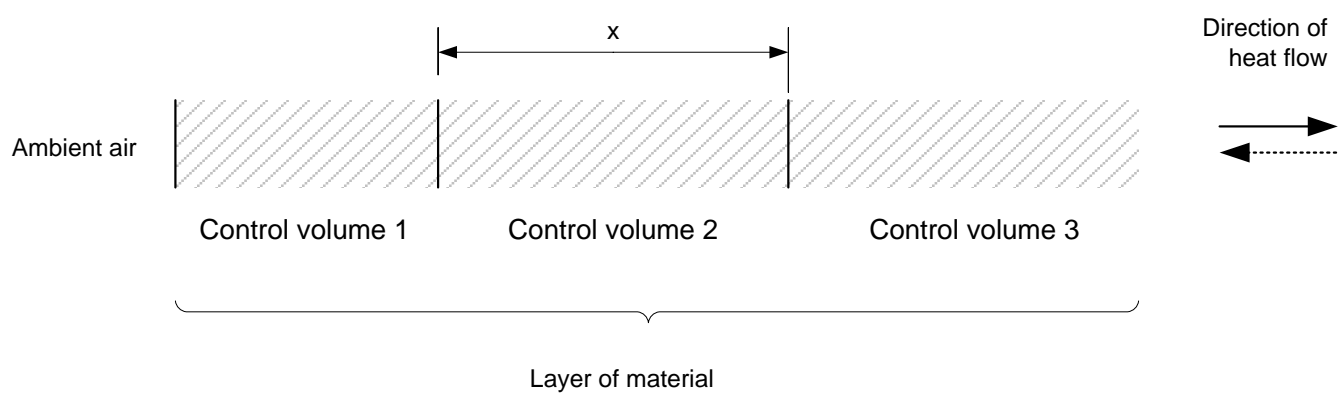

Figure 3 Numerical scheme based on the control volume method.

For a homogeneous material, the temperature $\mathrm{T}$ of the material enclosed in a control volume, $\Delta V$, of the area $A$ and the thickness $\Delta x$, is found from the following energy balance model

$$
\rho c \cdot \Delta V \frac{\Delta T}{\Delta t}=-A \cdot \Delta q \text { or } \quad C \frac{\Delta T}{\Delta t}=-\frac{\Delta q}{\Delta x}
$$

Where $C$ represents the volumetric heat capacity $\left(\mathrm{J} / \mathrm{m}^{3} / \mathrm{K}\right)$ and $q$ is the specific heat flow $\left(\mathrm{W} / \mathrm{m}^{2}\right)$.

For non-homogeneous materials, such as boards with a PCM integrated in the matrix of a base material, the left-hand side of equation (10) can be written as

$$
\omega \cdot C_{\text {base }} \frac{\Delta T}{\Delta t}+(1-\omega) \frac{\Delta H_{P C M}}{\Delta t}=\ldots
$$


where $\omega$ and (1- $\omega)$ are the volumetric shares of the base material and PCM in the control volume, respectively.

The control volume in a numerical scheme in Figure 3 is designed as a separate block in the IBPT library, in order to facilitate the refinement of the numerical grid. Based on the prescribed material properties and the geometry of the control volume, the flows to the neighbouring control volumes are calculated and passed through appropriate signals. Material properties can be defined in a separate block, termed 'Material properties', which is also enclosed in the control volume. As mentioned above, the library contains the originals of each unique block. In this way, any changes made in the original block are transferred through automatically established links to each instance of the block within the library, or within a model in Simulink, as depicted in Figure 4.

Note that the links can be also inhibited or fully broken if necessary. For example, the block containing material properties of a base material and a PCM, and termed in the example 'Material properties with PCM', is made from the copy of the block 'Material properties'. The links between these two blocks are broken so that any change in either of them cannot be passed to the other block. As a new block represents an upgraded version of another block, many of the former modelling efforts and solutions are preserved. This is, for example, the case with the block 'Control volume with PCM', which is made from the original block 'Control volume'. 


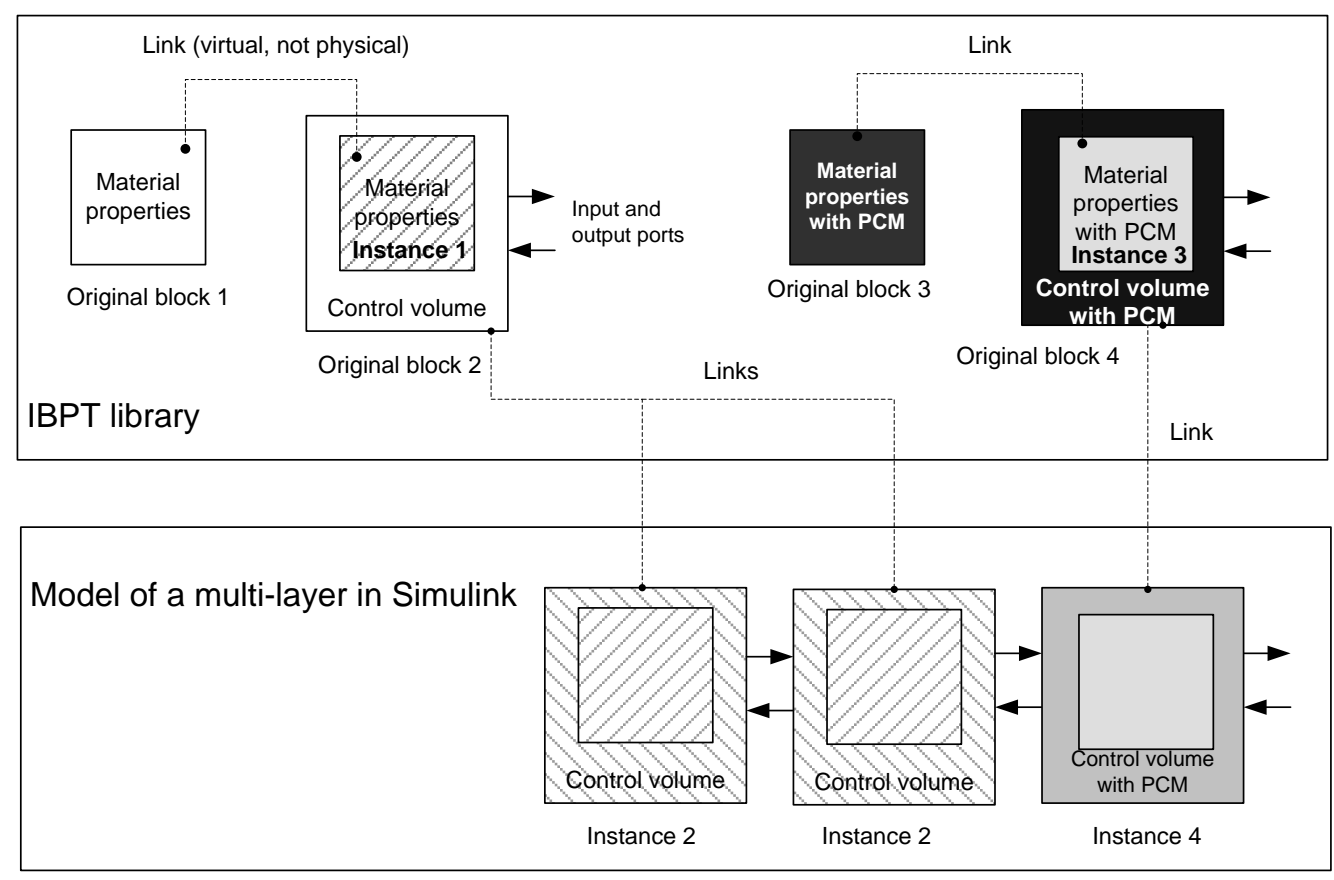

Figure 4 Organization of the IBPT library and the links with models in Simulink (a concept).

Thermal properties of the base material with PCM, as described by equation 10, are enclosed in the block 'Material properties with PCM'. The volumetric heat storage capacity of the PCM of type B is introduced in a table form and as a function of the temperature, as shown in Figure 5. The corresponding control volume block is then upgraded with new inputs where type and share of PCM in the volume can be specified (see Figure 5).

The numerical model of the PCM of type A is much more challenging. A solution has been found with the help of two enabled systems, where the one calculates (through integration) the mass of a liquid phase during melting, and the other the mass of the solid phase during solidification. The start of the melting or solidification processes is triggered by an increasing/decreasing temperature gradient of the PCM. During the simulation, the integrals within the enabled systems exchange their states; they must be reset at the end of each melting / solidification cycle, which is also accomplished through the system enabling (Figure 6). 


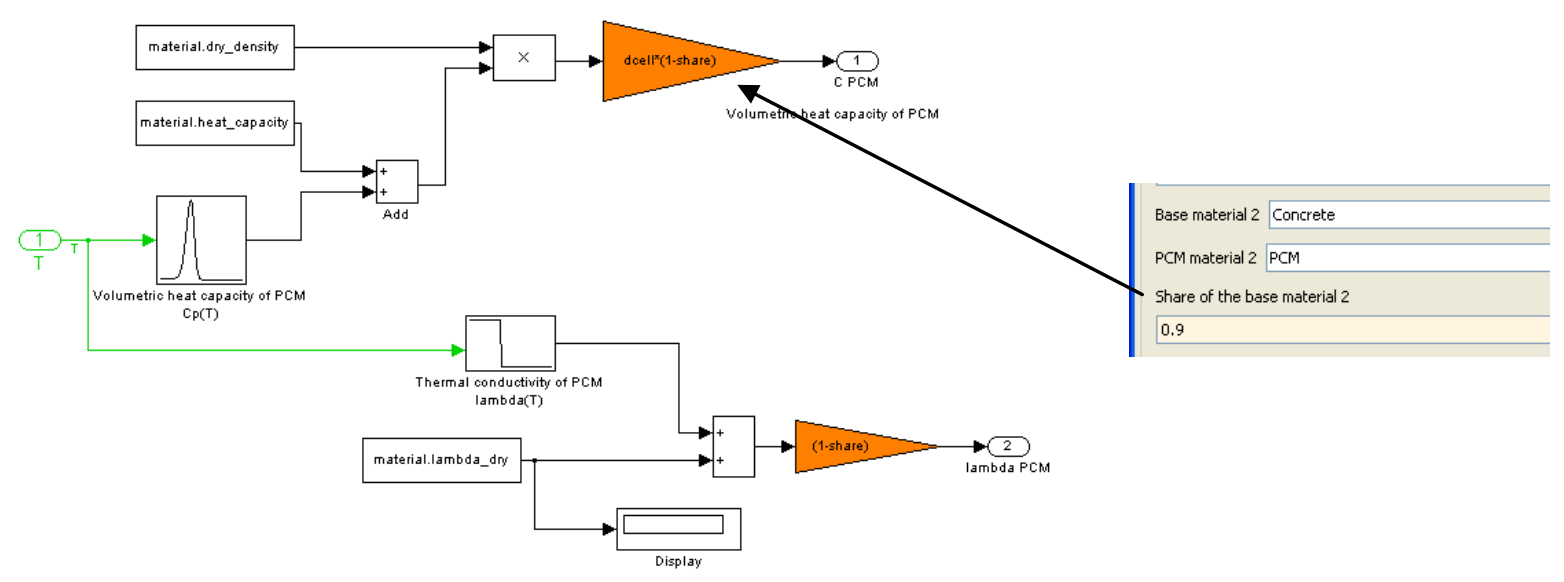

Figure 5 To the left: Thermal properties of the PCM of type B as presented in a Simulink model. To the right: specification of the share of a base material in a block mask.

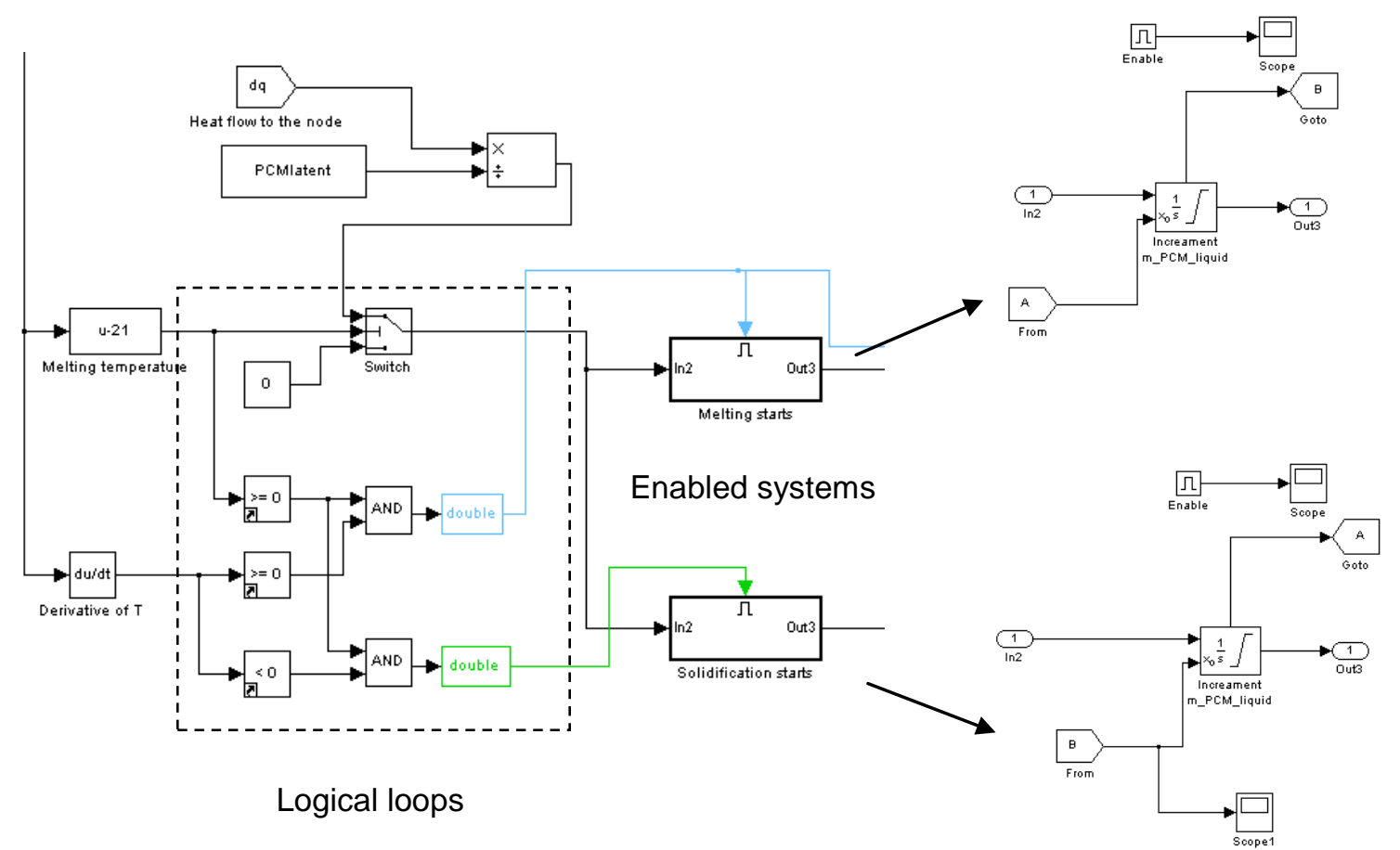

Figure 6 To the left: control routine for the start of the melting/solidification of PCM. To the right up/below: the integrals within the enabled blocks 'Melting starts' and 'Solidification starts' calculate the mass of melted and solidified PCM. The states of the integrals are exchanged through the ports named A and B. At enabling, the integrals are reset to zero states. 
An example of the results obtained with this model is presented in Figure 7. In the simulation, a slab is studied that is composed of pure concrete, $8.75 \mathrm{~cm}$ thick, and $1.25 \mathrm{~cm}$ thick composite made of a concrete and $1 \%, 10 \%$ and 30 vol. \% of PCM. The side of the slab with PCM is exposed to periodically varying boundary temperature in the range of $10{ }^{\circ} \mathrm{C}$ to $30{ }^{\circ} \mathrm{C}$ and with a period of $24 \mathrm{~h}$. On the other side of the slab, the temperature is kept at 20 ${ }^{\circ} \mathrm{C}$. The thermal properties of the PCM are fictitious and invented only for the purpose of testing the numerical model; these are: the volumetric heat capacities of the solid and liquid phase, $0.5 \mathrm{MJ} / \mathrm{m}^{3} \mathrm{~K}$ each, the latent heat of melting, $0.2 \mathrm{MJ} / \mathrm{kg}$, the thermal conductivity, 0.5 $\mathrm{W} / \mathrm{mK}$ and the melting point, $2{ }^{\circ} \mathrm{C}$. The properties of concrete can be found in Table 1 . The effect of latent heat storage can be seen as flatten tops of the temperature profiles in the layer of concrete with PCM. The amount of melted PCM decreases as the volumetric share of PCM increases.
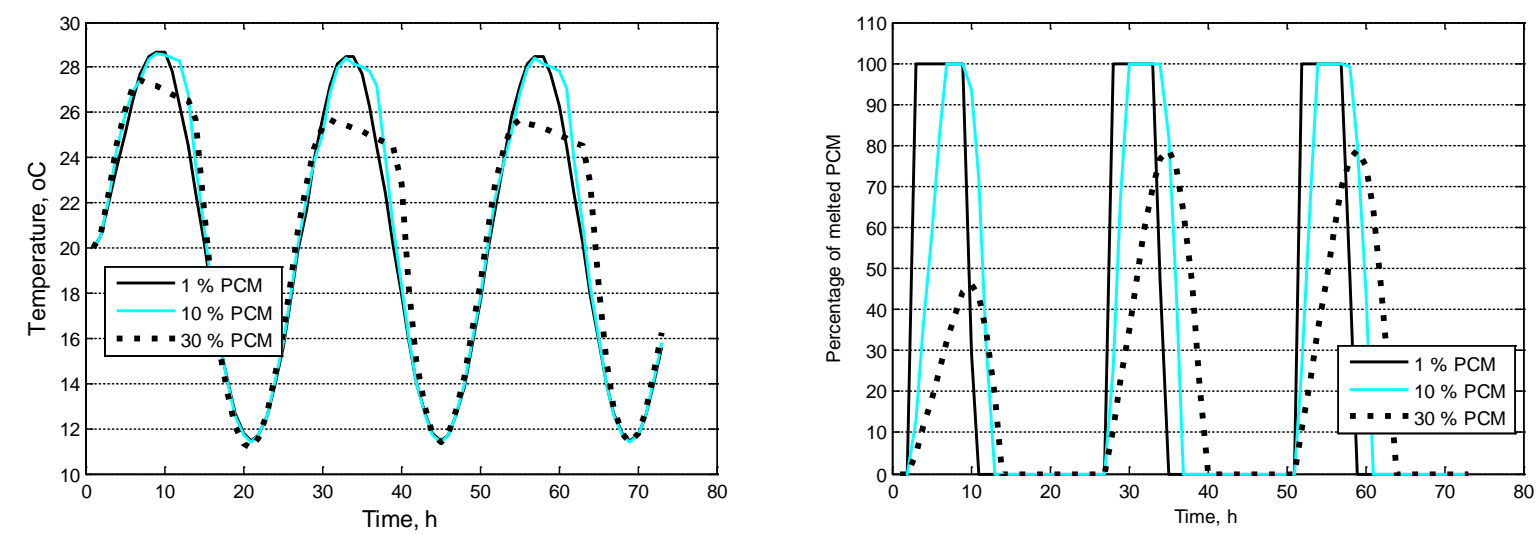

Figure 7 To the left: Temperature of the layer of concrete with $1 \%$ and $10 \%$ vol. of PCM. To the right: Percentage of melted PCM in respect to the volumetric share in the concrete.

The model performs for the most part properly with all constrains that are created by the logical loops and the enabled systems (as in Figure 6). The concrete slab has been discretized in four non-uniform volumes (a surface volume of $1.25 \mathrm{~cm}$ and three inner volumes of $2.5 \mathrm{~cm}$ ) while the PCM layer has been treated as one control volume $(1.25 \mathrm{~cm})$. A 
built-in ordinary differential equation solver ODE23tb of Simulink has been used in all simulations. This solver is an implementation of an implicit Runge-Kutta formula. It has ability to modify its step sizes during the simulation and it provides error control and zero crossing detection. The choice of the ode solver has been based only on the simulation efficiency. Simulations become unstable when (unrealistically) low latent heat of the PCM is specified, i.e. in the range of $2000-20000 \mathrm{~J} / \mathrm{kg}$. The interpretation of this numerical problem is that these low latent heat values lead to too fast transitions between the melting and the solidification states, i.e. between the enabled systems, so the whole system becomes undefined. There might be other solutions for the model of type A, as well as for the spatial grid and the ODE solver that provide stable simulations at any range of input data. The problem has not been further investigated because, currently, there is no practical interest to improve the simulations of physically unrealistic PCMs. Besides, according to the literature, the PCMs in building materials are usually found as blends of different PCMs so the focus of the investigations has been moved from single components PCMs (type A) to the PCMs blends that melt over a range of temperatures (type B).The next section provides details of the verification tests of the IBPT models of the PCM type B.

\subsection{Level 2 - Verification of the IBPT model of a wall with PCM}

Annex 23, Task C (Johannes et al.2011) provides the benchmark for the verification of a numerical model of a wall with the PCM of type B. The benchmark includes nine onedimensional case studies (one-dimensional analysis), ranging from a single layer of a PCM to a multi-layered wall composed of the PCM and another single material (concrete or insulation).The specifications of building materials, the wall compositions and the test cases are provided in Tables 1-2. The thermal properties of the PCM are summarized in Figure 8. 
Table 1 Thermal properties of materials as defined in Annex 23.

\begin{tabular}{|l|c|c|c|}
\hline Material & Thermal conductivity, $[\mathrm{W} / \mathrm{mK}]$ & Density, $\left[\mathrm{kg} / \mathrm{m}^{3}\right]$ & Specific heat capacity, $[\mathrm{J} / \mathrm{kg} . \mathrm{K}]$ \\
\hline Concrete & 1.2 & 2000 & 1000 \\
\hline Insulation & 0.04 & 50 & 1000 \\
\hline
\end{tabular}

Table 2 Case studies of the benchmark of Annex 23

\begin{tabular}{|l|l|l|}
\hline Case & External layer & Internal layer \\
\hline 1: P5 & $5 \mathrm{~mm}$ of PCM & - \\
\hline 2: P10 & $10 \mathrm{~mm}$ of PCM & - \\
\hline 3: P50 & $50 \mathrm{~mm}$ of PCM & - \\
\hline 4: C30+P10 & $30 \mathrm{~mm}$ of concrete & $10 \mathrm{~mm}$ of PCM \\
\hline 5: P10+C30 & $10 \mathrm{~mm}$ of PCM & $30 \mathrm{~mm}$ of concrete \\
\hline 6: C200+P10 & $200 \mathrm{~mm}$ of concrete & $10 \mathrm{~mm}$ of PCM \\
\hline 7: P10+C200 & $10 \mathrm{~mm}$ of PCM & $200 \mathrm{~mm}$ of concrete \\
\hline 8: $\mathrm{I} 100+\mathrm{P} 10$ & $100 \mathrm{~mm}$ of insulation & $10 \mathrm{~mm}$ of PCM \\
\hline 9: P10+I100 & $10 \mathrm{~mm}$ of PCM & $100 \mathrm{~mm}$ of insulation \\
\hline
\end{tabular}

In the benchmark, the internal (left-hand side) boundary temperature is constant and equal to $12{ }^{\circ} \mathrm{C}$. The external temperature increases instantly from $12{ }^{\circ} \mathrm{C}$ to $32{ }^{\circ} \mathrm{C}$ at the start of simulation. The initial temperature of the wall is $12{ }^{\circ} \mathrm{C}$. The convective heat transfer coefficients of $8 \mathrm{~W} / \mathrm{m}^{2} \mathrm{~K}$ and $2.5 \mathrm{~W} / \mathrm{m}^{2} \mathrm{~K}$ are assigned as two constant values at the external and internal wall boundaries. All radiation heat exchange with the surroundings is neglected.
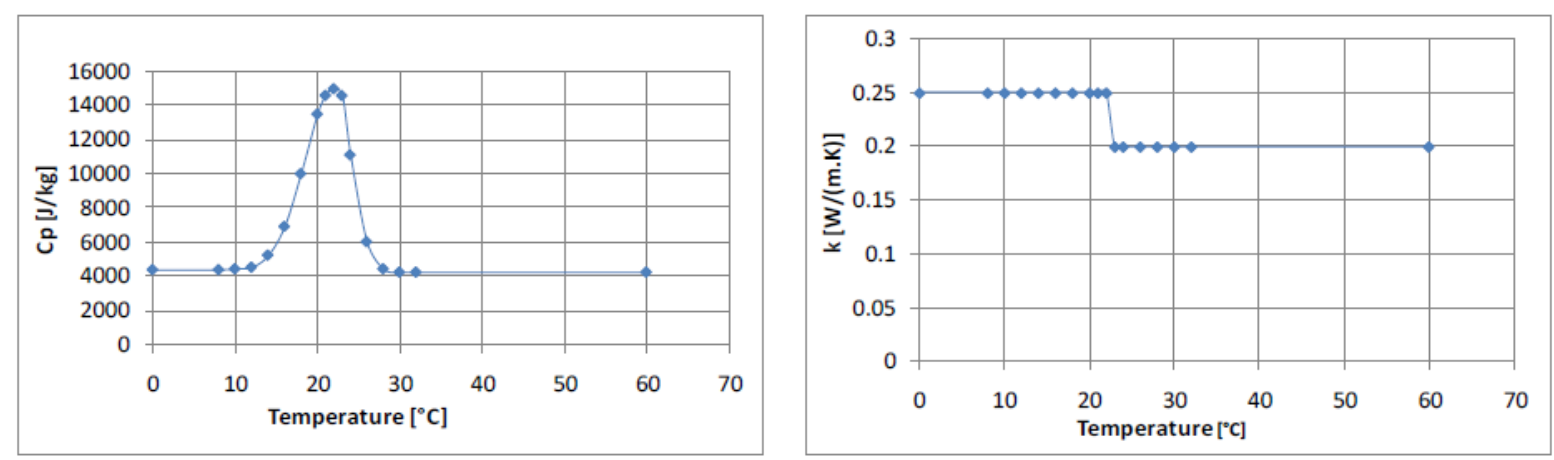

Figure 8 Apparent volumetric heat capacity of PCM (to the left) and thermal conductivity (to the right), as defined in Annex 23. The density of the PCM is considered constant and equal $1100 \mathrm{~kg} / \mathrm{m} 3$.

Temperatures at the interior side of the benchmark walls, as obtained by the IBPT model, are presented in Figure 9 together with two other solutions from Task C. Note that none of these solutions have been indicated as a reference solution of Task C. Generally, abetter agreement is obtained between the IBPT solution and the solution indicated by marker 
'o' (referred in Task C as the solution from France,) than with the solution indicated by ‘*'(referred as the solution from Norway). The solution from France has been obtained by a TRNSYS model of a wall with PCM (type 260), for which results of experimental verifications can be found in Kuznik et al. (2010). Some noticeable differences between the IBPT solution and the one of TRNSYS are present in the first three cases where single layers of the PCM are studied. As it can be seen, the temperature rise at the interior of the slab is faster in the IBPT solution, differing by $1{ }^{\circ} \mathrm{C}$ at maximum for the slab of minimum thickness (10 mm, case 1). These differences are smaller (about $0.5{ }^{\circ} \mathrm{C}$ or less) as the thickness of the slab increases to $30 \mathrm{~mm}$ and $50 \mathrm{~mm}$ (case 2 and case 3). Similar differences cannot be observed when other materials are combined with the PCM (cases 4-9). One possible reason for the differences can be found in the way the volumetric heat capacity $C$ and the thermal conductivity $k$ of the PCM are modelled. In the IBPT approach, the shapes of the curves are defined from the tabulated values from Task C, while the subtotals are found by linear interpolation during simulations. In TRNSYS, an analytical expression is used for $C$ (Johannes et al. 2011). Although in the range of the discrepancies found during experimental validation of the TRNSYS model (see Kuznik et al. 2010), the observed differences should be taken with attention in cases where only PCMs are studied and under similar rates of change of boundary temperatures. Opposite can be observed when the IBPT results are compared to the solution marked with '*' (the solution from Norway), i.e. a better agreement is found in the first three cases than in the remaining six. Further conclusions cannot be made in this respect as the modelling details of the Norwegian model are not presented in Task C.

In all IBPT solutions, the slab has been discretized by 22 control volumes. When two materials have been studied, 11 control volumes have been allocated to each of them. A uniform thickness is applied to all control volumes enclosed by the same material, except for the volumes placed at the exterior or the interior boundary of the slab, whose thicknesses are 

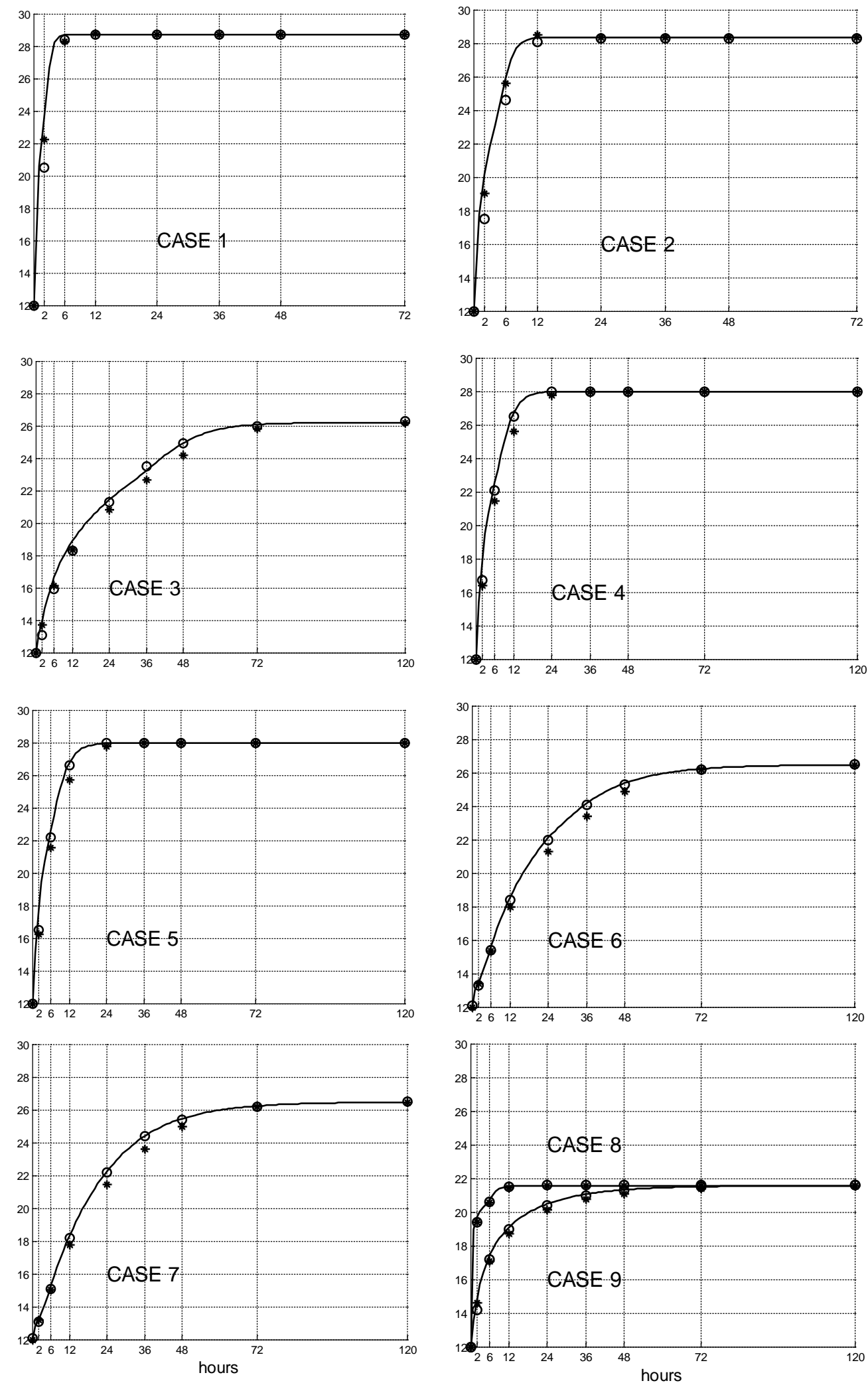

Figure 9 Evolution of the temperature at the interior of the slab as obtained by the IBPT model (solid line) and two other solutions from Annex 23(marker 'o' for the solution from France and '*' for the solution from Norway). 
determined as half of the thickness of the next adjacent volume. Consequently, the spatial resolution changes from case to case; the finest can be found in case 1 , with $0.5 \mathrm{~mm}$ for inner control volumes and $0.25 \mathrm{~mm}$ for the side volumes, and the coarsest in cases 6 and 7 where the inner and the side (left-hand/right-hand)control volumes of the concrete layer are $19.0 \mathrm{~mm}$ and $9.5 \mathrm{~mm}$ respectively. Of course, much finer spatial resolutions are possible. However, these would require rearrangement of the blocks in the model for each particular case. For the sake simplicity, an optimal number of control volumes have been selected and then applied throughout the whole benchmark.

\subsection{Level 3 - Validation of the IBPT model of a room with PCM wallboards}

Kuznik and Virgone (2009) conducted a serial of experiments in a test room with a purpose of evaluating the effects of a PCM composite wallboard on indoor climate in the room. Effects of the PCM were investigated comparing the results obtained with and without composite wallboards for three weather conditions: a summer day, a winter day and a mid-season day. Since these experiments were performed under variable but controlled environments, the data collected thereby have been found appropriate for the validation of the IBPT room model with PCMs.

The test room of size $3.1 \times 3.1 \times 2.5 \mathrm{~m}^{3}$ was built inside another chamber that acted as a thermal guard for three walls, the ceiling and the floor; the fourth and fully glazed wall was in contact with an air chamber where outdoor weather conditions were created by the means of an air conditioner and a solar simulator. A simplified layout of the room is shown in Figure 10. The tested PCM constituted of $60 \%$ of microencapsulated paraffin within a polymer, and it was formed as a flexible sheet of $5 \mathrm{~mm}$ thickness. These sheets were built in the north, west and east walls, behind the layer of plaster. Thermal properties of the PCM and other building materials of the test room are provided in Appendix. 

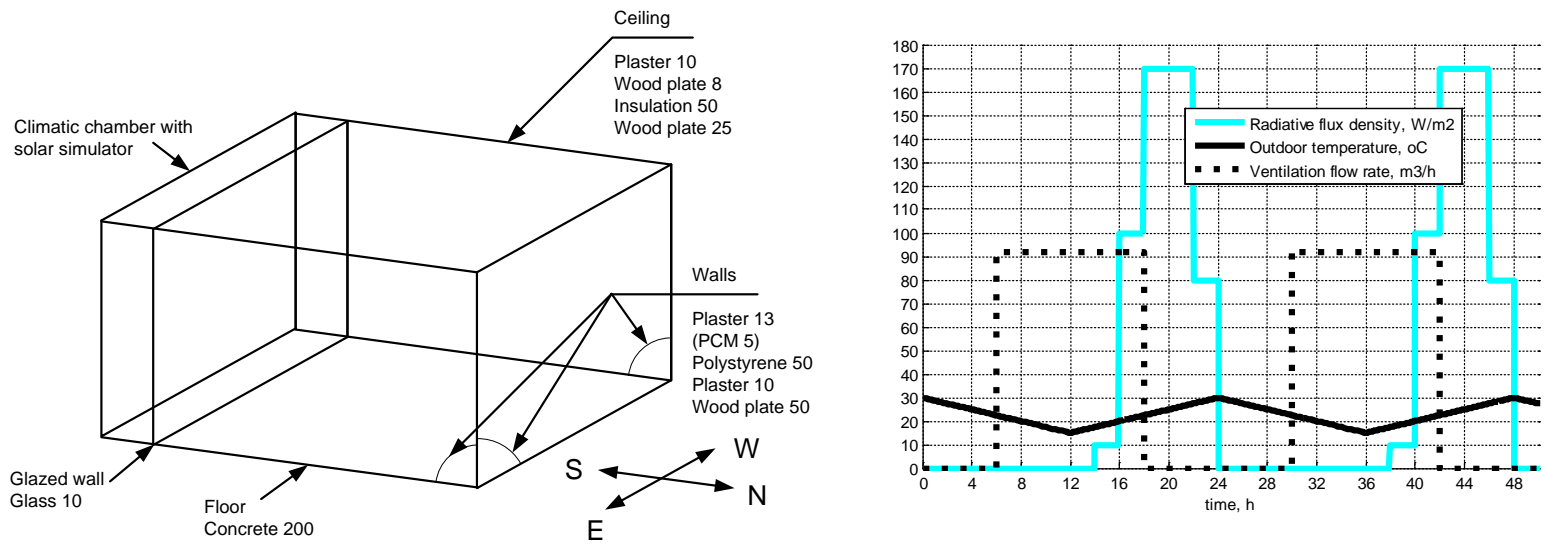

Figure 10 To the left: the test room. To the right: outdoor air temperature, solar radiation intensity and the ventilation flow rate as implemented in the numerical simulations for the summer day case.

In the climate simulator, the outdoor air temperature was increased / decreased linearly between a minimum and a maximum value, over a period of twelve hours. The temperature range for the summer season was $15{ }^{\circ} \mathrm{C}$ to $30{ }^{\circ} \mathrm{C}$, for the mid-season $10{ }^{\circ} \mathrm{C}$ to $25{ }^{\circ} \mathrm{C}$ and $5{ }^{\circ} \mathrm{C}$ to $20{ }^{\circ} \mathrm{C}$ for the winter season. The solar simulator created variable and fairly repeatable radiation load; the actual radiation load (as provided in Kuznik and Virgone (2009)) has been somewhat simplified in the simulations, according to the scheme shown in Figure 10. During summer and winter conditions, the climate in the cell was partly regulated by ventilation and heating, respectively. In the first, whenever the outdoor temperature was below $22.5{ }^{\circ} \mathrm{C}$, the test cell was ventilated by outdoor air and at a constant rate of $3.8 \mathrm{ACH}$ (or $92 \mathrm{~m}^{3} / \mathrm{h}$ ). In the letter, a heater of $1500 \mathrm{~W}$ maintained the indoor temperature at $20{ }^{\circ} \mathrm{C}$ whenever needed. The temperature in the thermal guard was kept at $20.5^{\circ} \mathrm{C}$ throughout the all experiments.

The numerical model of the test room is composed of ordinary IBPT blocks, i.e. window, floor, roof and indoor air, and from the wall block with the PCM type B from section 3.2. The blocks are then connected by pre-defined signals, which form the IBPT interface, as shown in Figure 11. These signals pass the information about physical states, transfer coefficients and flows at the surface of a component, or about its spatial position, (IBPT 
2002). As mentioned above, the type and arrangement of the data in these signals are definite at this level of modelling, and this has been the standard procedure since the library has been established. Thus, none of the above presented changes that have been made through the process of upgrading of an ordinary IBPT wall block into a wall with PCM have affected the standard interface. This convenience is crucial for increasing the volume of the library as it allows a user to develop independently new models, and still be able to combine these models with the other blocks in the library.

Figure 11 The IBPT model of the test room from Figure 10.

In conformity with the experiments, the calculations have been performed for three consecutive days and the results of indoor air temperature for the last two days are presented 
together with the measured data in Figure 12. As it can be seen, the numerical model calculates correctly variations and magnitudes of indoor air temperature for all cases presented. There are also some noticeable differences between the measured and the calculated data. For example, the measurements indicate existence of temperature stratification inside the room (at $85 \mathrm{~cm} / 170 \mathrm{~cm}$ from the floor, all cases without PCM), while the model shows a mean temperature in the room. This is due to the model limitations - all IBPT zone models are based on the assumption of a well mixed air in the zone. Another difference can be seen during the mid-season, in the room with PCMs, where the calculated temperature amplitudes appear more dampened than the measured ones. It has been found that this discrepancy can be assigned to a simplified model for long-wave radiation in the room, as it is further exemplified in Appendix. Finally, the numerical model shows that the heating of the room during the winter season starts at $20{ }^{\circ} \mathrm{C}$, as specified in the description of the experiment, while the measurements show that the actual set-point temperature is approximately at $19{ }^{\circ} \mathrm{C}$. A better agreement is obtained after the set -point temperature is adjusted to $19{ }^{\circ} \mathrm{C}$ in the calculations, as shown in Appendix.

Besides the results of air temperature, the validation results for the surface wall temperatures are also satisfactory (see Appendix). Based on these findings, the IBPT model of the room with PCM is considered validated and capable of simulating the effects of PCMs in real operating conditions. This final numerical example is provided in the next section.

\section{Numerical evaluation of the effects of PCM in a room under realistic operating conditions}

The interest for whole building simulation models with PCMs has been shown, among others, within the European Commission co-funded research project focusing on new network technologies for energy efficient and sustainable districts ('New $\mu$-CHP network technologies for energy efficient and sustainable districts', grant no 260105). For the purpose of 
exemplifying the effects of PCM on the thermal performance of a building in use, a

provisional case study is constructed and described hereafter.

The case study focuses on thermal comfort and energy demand for heating and cooling of an air conditioned zone, within a single family house. The layout of the zone is shown in Figure 13. The zone is defined by three external and a single internal wall, a floor of type slab on the ground and a roof. The size of the floor area is $42 \mathrm{~m}^{2}$ and the height is $2.5 \mathrm{~m}$. Table 3 summarizes details about the construction of the building envelope, which has been specified in conformity with the interest of the project.

It is assumed that the zone is used as a living room of a family of four people. During the occupancy hours, i.e. between 6 am and $9 \mathrm{pm}$, the thermal comfort in the zone is held within a temperature range of $21^{\circ} \mathrm{C}-25^{\circ} \mathrm{C}$, and between $17^{\circ} \mathrm{C}$ and $28{ }^{\circ} \mathrm{C}$ for the remaining hours. The zone is ventilated by outdoor air. The air change rate is set to $0.8 \mathrm{ACH}$ during the occupancy hours and to $0.6 \mathrm{ACH}$ in the remaining ones. Internal gains in the zone are split into a constant part of the rate of $200 \mathrm{~W}$, which originates from the appliances in the room, and into a scheduled part that originates from the people in the zone. It is assumed that up to four people can be present in the room at the same time and that each person generates 120 $\mathrm{W}$. The maximum heat load from the people in the zone, i.e. $480 \mathrm{~W}$ is then multiplied with the percentages of occupancy provided in Figure 13, which are scheduled in respect to the time of a day, and the day in a week. The weather data for Munich, Germany are used in simulations, based on a test year as generated by the climate modelling programme Meteonorm (Meteotest 2009).

Several comparative tests are made in order to exemplify the effects of PCM in the walls. For this purpose, two versions of the building envelope are tested, termed 'well insulated' and 'less insulated'. In the former case, the insulation thicknesses of the exterior walls and the roof are specified according to Table 3 , while in the latter, these are set to 0.06 
$\mathrm{m}$. The U-values of the windows are 1.4 and $2.46 \mathrm{~W} / \mathrm{m}^{2} \mathrm{Kin}$ the respective case. Besides the insulation efficiency, the designs of the building envelope are compared in respect to the placement and share of PCM in the gypsum boards of the walls (internal and external). The thermal properties of the PCM from section 3.2 are used in all studied cases to narrow the amount of data in the study, although PCMs with other melting ranges can be found more appropriate.
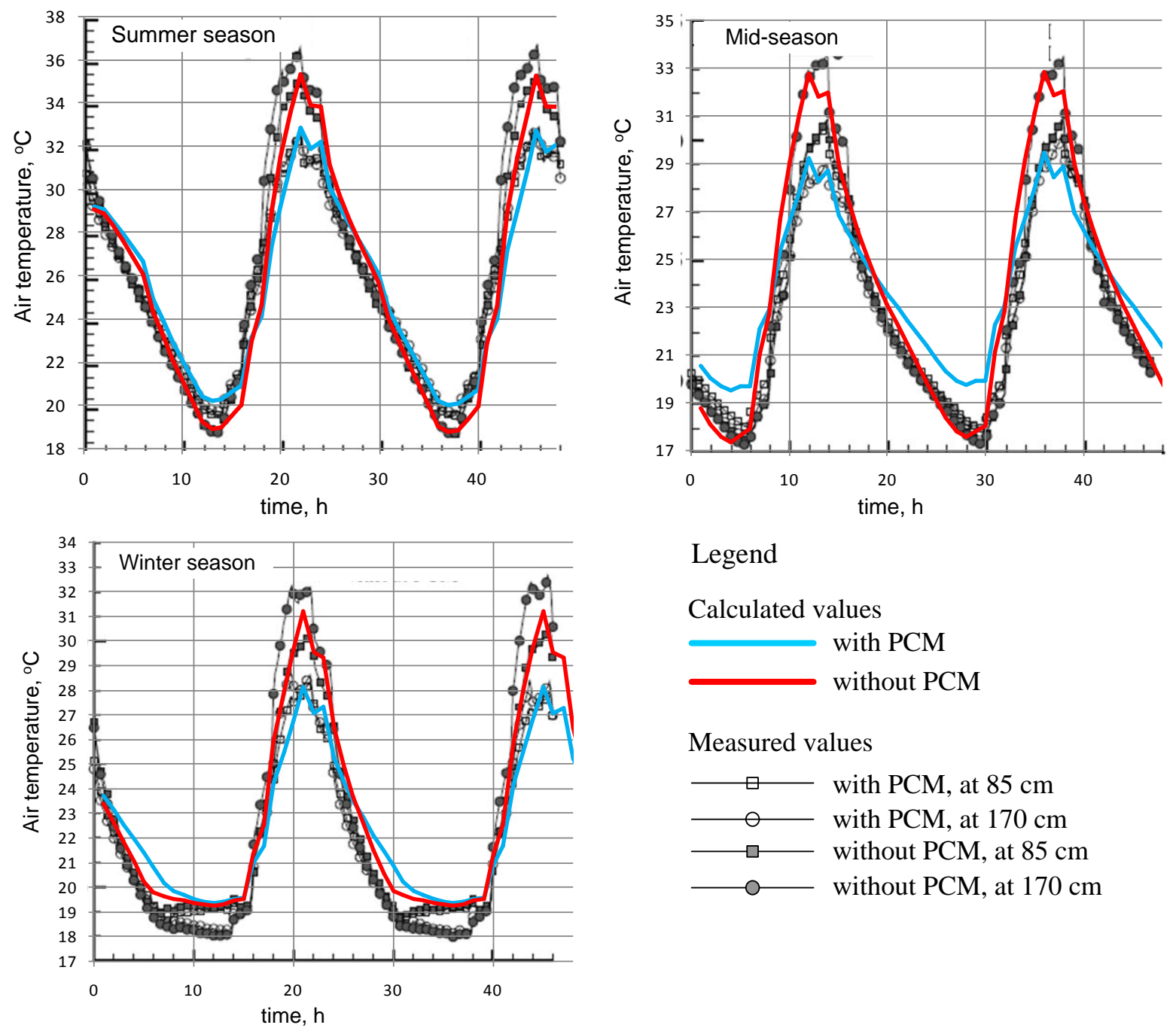

Legend

Calculated values

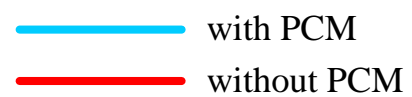

Measured values

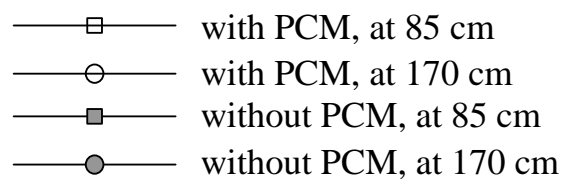

Figure 12 Measured and calculated air temperature in the test room for all seasons.

For the reason of simplicity, the floor is thermally decoupled from the ground by a $1 \mathrm{~m}$ thick insulation layer (see Table 3). Note also that all internal gains are defined as convective 
and that the heating and cooling of the zone in the simulations are facilitated through heating and cooling systems with an indefinite heat capacity.
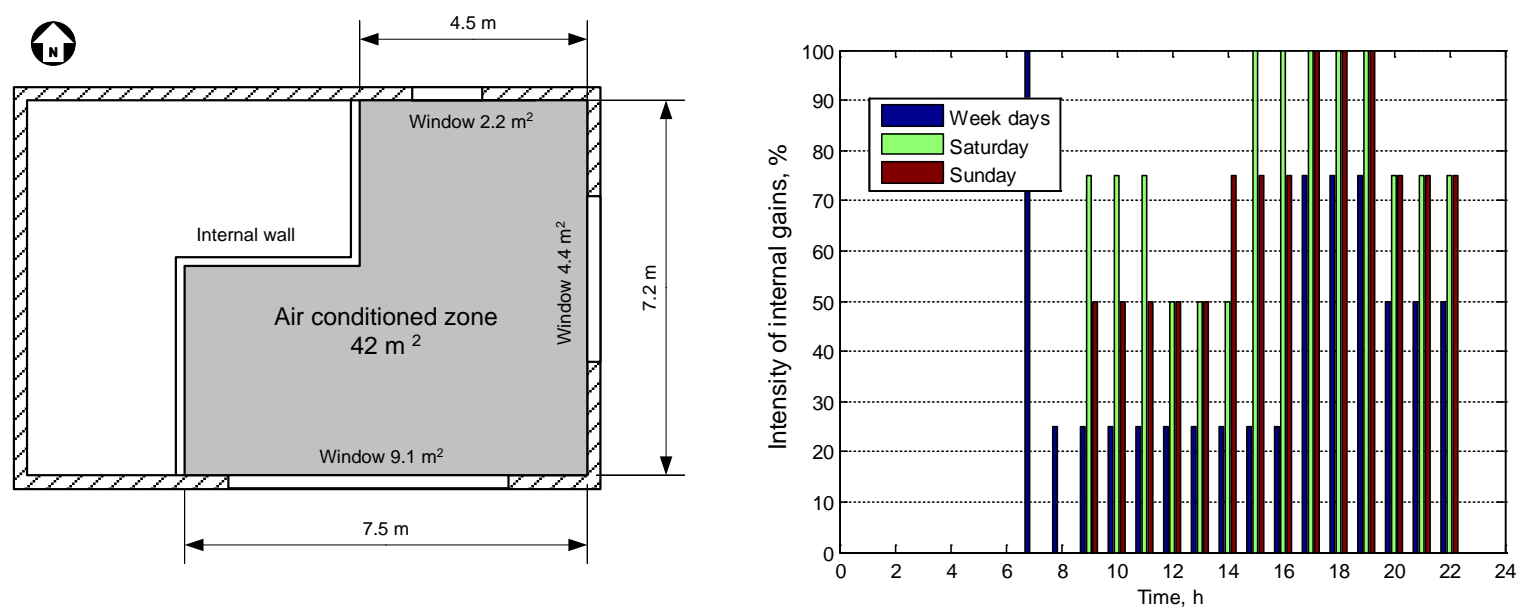

Figure 13To the left: layout of the studied zone. To the right: Daily schedules for internal gains in the zone.

Table 3 Specification of the building envelope of the studied zone

\begin{tabular}{|c|c|c|c|c|c|}
\hline $\begin{array}{l}\text { Layout of the wall } \\
\text { from interior to } \\
\text { exterior } \\
\text { Externalwall }\end{array}$ & $\begin{array}{c}\text { Thermalconductivit } \\
\text { y, } \\
{[\mathrm{W} / \mathrm{mK}]}\end{array}$ & $\begin{array}{l}\text { Density } \\
\text { [kg/m3] }\end{array}$ & $\begin{array}{c}\text { Specific heat } \\
\text { capacity } \\
{[\mathrm{J} / \mathrm{kgK}]}\end{array}$ & $\begin{array}{c}\text { Thickness } \\
{[\mathrm{m}]}\end{array}$ & $\begin{array}{c}\text { Overal U value } \\
\text { [W/m2K] }\end{array}$ \\
\hline Plaster board & 0.16 & 900 & 840 & 0.012 & \\
\hline Gypsum board & 0.2 & 1200 & 800 & 0.024 & \\
\hline Insulation & 0.033 & 30 & 800 & 0.18 & \\
\hline Gypsum board & 0.2 & 1200 & 800 & 0.024 & \\
\hline Timber & 0.14 & 600 & 1500 & 0.03 & \\
\hline \multicolumn{5}{|l|}{ Roof } & 0.167 \\
\hline Plaster board & 0.16 & 900 & 840 & 0.012 & \\
\hline Gypsum board & 0.2 & 1200 & 800 & 0.024 & \\
\hline Insulation & 0.033 & 30 & 800 & 0.28 & \\
\hline Gypsumboard & 0.2 & 1200 & 800 & 0.024 & \\
\hline Roofdeck & 0.14 & 600 & 1500 & 0.03 & \\
\hline \multicolumn{5}{|l|}{ Floor } & 0.111 \\
\hline Carpet & 0.1 & 1800 & 1000 & 0.01 & \\
\hline Concrete slab & 0.41 & 1000 & 900 & 0.03 & \\
\hline Insulation & 0.039 & 200 & 1250 & 1 & \\
\hline \multicolumn{6}{|l|}{ Internalwall } \\
\hline Gypsumboard & 0.2 & 1200 & 800 & 0.024 & \\
\hline Insulation & 0.033 & 30 & 800 & 0.3 & \\
\hline Gypsumboard & 0.2 & 1200 & 800 & 0.024 & \\
\hline
\end{tabular}


The numerical model of the room has been built in a similar way as the one from

section 3.3. The model of the air zone is exactly the same, together with all assumptions about the convective and radiative heat exchange in the zone (more details can be found in Appendix).

\subsection{Effects of the PCM on the thermal comfort in the room}

A major difficulty in assessing the performance of PCM in buildings, in operating conditions, is how to separate the effects of PCM from other heat transfer processes that occur at the same time. As it can be seen in Figure 14, the use of PCM in the walls of the air conditioned zone from the case study does influence the indoor air temperature. However, according to the simulations, these effects are rather small and it may be difficult to evaluate them by measurements in real time due to a number of possible disturbances in indoor environment.
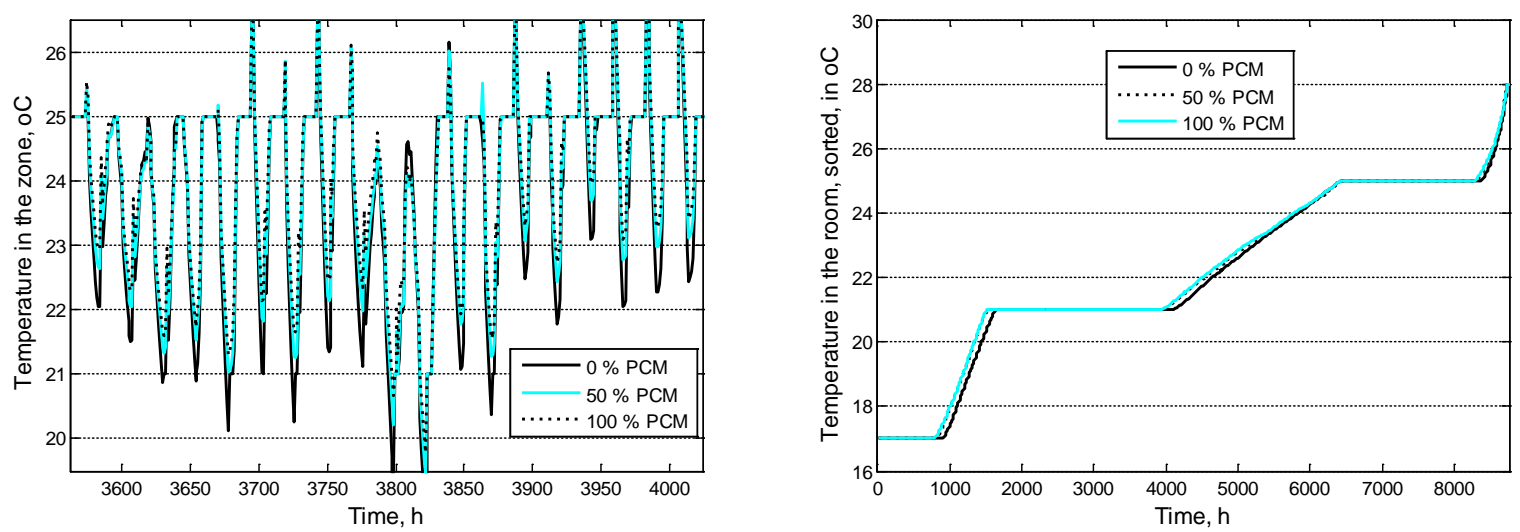

Figure 14To the left: indoor temperatures in the room for the case 'low' insulation efficiency, and in respect to the volume percentage of the PCM in the interior wall boards. To the right: the same results sorted in ascending order.

\subsection{Effects of the PCM on the energy demand for heating and cooling of the room}

The results of annual energy demands for heating and cooling of the zone are summarized in Table 4. The five cases presented differ by the insulation efficiency of the exterior walls (low or high) and by the percentage of the PCM in the interior plaster board (0\%, $50 \%$ and 100 
\%). Note that the plaster board with PCM and the board with $100 \%$ of the PCM are just theoretical, without any implications of specific products.

According to the results, modest savings are achieved by including the PCM in the plaster boards, i.e. between $5 \%$ and $8 \%$. Even if larger savings are achieved with the better insulation efficiency of the building envelope, it is questionable if these savings are measurable in real operation due to a number of uncertainties that may influence the results. Besides, the maximum savings of approximately $8 \%$ would require a board composed of 100 \% of PCM, which could be difficult to implement as such in buildings.

Table 4 Annual heating and cooling demand of the room, with thermal comfort between 21 and $25{ }^{\circ} \mathrm{C}$.

\begin{tabular}{|c|c|c|c|c|}
\hline \multirow{2}{*}{$\begin{array}{c}\text { Volume percentage of } \\
\text { PCM in the interior } \\
\text { boards of all the walls }\end{array}$} & \multirow{2}{*}{$\begin{array}{c}\text { Insulation } \\
\text { standard of the } \\
\text { exterior walls }\end{array}$} & Total heating and cooling demand, kWh/year & \multirow{2}{*}{$\begin{array}{c}\text { \% savings in } \\
\text { total demand }\end{array}$} \\
\cline { 3 - 5 } & Low & 6136 & Cooling only & \\
\hline $50 \%$ & Low & 5815 & 2263 & Reference \\
\hline $100 \%$ & Low & 5665 & 1983 & 5.2 \\
\hline $0 \%$ & High & 5541 & 2458 & Reference \\
\hline $100 \%$ & High & 5110 & 2203 & 7.8 \\
\hline
\end{tabular}

One reason for the small energy savings with PCMs is a narrow band of free running temperature in the room during the daytime, i.e. between $21{ }^{\circ} \mathrm{C}$ and $25{ }^{\circ} \mathrm{C}$, when the highest heat load in the room occurs. The melting of the PCM takes place over a wider range of temperatures, approximately between $12{ }^{\circ} \mathrm{C}$ and $28{ }^{\circ} \mathrm{C}$ (see Figure 10), indicating that the latent heat of the PCM is not fully utilized in this example. Therefore, another set of simulations is performed with the set point temperatures of $21{ }^{\circ} \mathrm{C}$ and $28{ }^{\circ} \mathrm{C}$ during the daytime. The remaining working conditions are specified as in the previous analysis. The results of these simulations are summarized in Table 5. As expected, substantially larger energy savings are achieved with a wider band of free running temperatures in the room. The most interesting result, i.e. the highest saving of the total energy for heating and cooling of the room is obtained by placing the PCM board behind the gypsum wall board. This arrangement 
of the boards might have some other practical benefits such as mechanical protection of the PCM board, and deserves further investigations. Note however that the total U-value of the wall is slightly changed in respect to the reference wall, because the PCM board behind the gypsum wall board is introduced as an additional layer in the wall. The results for this wall arrangement are only indicative.

Table 5Annual heating and cooling demand of the room, with thermal comfort between 21 and $28{ }^{\circ} \mathrm{C}$.

\begin{tabular}{|c|c|c|c|c|}
\hline \multirow{2}{*}{$\begin{array}{l}\text { Volume percentage of } \\
\text { PCM in the interior } \\
\text { boards of all the walls }\end{array}$} & \multirow{2}{*}{$\begin{array}{l}\text { Insulation } \\
\text { standard of the } \\
\text { exterior walls }\end{array}$} & \multicolumn{2}{|c|}{ Total heating and cooling demand, $\mathrm{kWh} /$ year } & \multirow{2}{*}{$\begin{array}{l}\text { \% savings in } \\
\text { total demand }\end{array}$} \\
\hline & & Total & Cooling only & \\
\hline $0 \%$ & Low & 6583 & 2189 & Reference \\
\hline $100 \%$ & Low & 5828 & 1789 & 11.5 \\
\hline $\begin{array}{l}100 \% \text {, behind the } \\
\text { gypsum wall board }\end{array}$ & Low & 5370 & 1315 & 18.4 \\
\hline $0 \%$ & High & 5795 & 2337 & Reference \\
\hline $100 \%$ & High & 4886 & 1850 & 15.7 \\
\hline $\begin{array}{l}100 \% \text {, behind the } \\
\text { gypsum wall board }\end{array}$ & High & 4547 & 1723 & 21.5 \\
\hline
\end{tabular}

\section{Conclusions}

This paper comprises modelling and simulations of building components and whole buildings with PCMs, by using a modular simulation toolbox IBPT. The modelling of PCMs have been exemplified on three levels: at the level of a single material, at the level of a building envelope and at a level of whole building in order to illustrate the benefits of multi-domain modelling.

At the level of component, two modelling approaches of the performance of PCMs in the melting region have been presented and discussed. In the first approach, which is suited for a PCM that melts at a constant temperature (type A), the temporal change of liquid and solid phase is calculated from combined energy and mass balance equations. In the second approach, the heat realise /storage during solidification/melting of PCMs is described by apparent volumetric heat capacity over a range of melting temperatures (type B). It has been shown that the performance of PCMs of type B can be readily modelled by presenting their 
apparent volumetric capacity as a temperature dependent variable. The numerical solution for PCMs of type A has turned more complicated as it has incorporated logical loops and enabled systems of the Simulink ${ }^{\circledR}$ toolbox. Numerical issues have been identified during simulations of PCMs of type A, however only in the range of unrealistically low latent heats of melting, i.e. in the range of $200-20000 \mathrm{~J} / \mathrm{kg}$.

Both models of PCMs have been integrated in the existing wall models of the IBPT library by utilizing the modular structure of the library. The IBPT model of a wall with a PCM of type B has been verified according to a normative benchmark. The model has performed well in all nine test cases in the benchmark. Besides, results of validation tests of the IBPT model of a test room with PCM integrated in the walls (PCM of type B) are provided and discussed. A similar model is then used in a tentative case study, for the purpose of evaluating the effects of PCMs in buildings in real operating conditions. The results of the simulations suggest that the effects of PCMs in buildings are rather case sensitive; the annual savings of total energy for heating and cooling vary between $5 \%$ and $21 \%$, depending mainly on the thermal comfort in the building and the placement of PCM in the building envelope.

The hierarchical organisation of the IBPT library and the multi-domain modelling environment of Simulink ${ }^{\circledR}$ have facilitated straightforward and efficient introduction of the PCM models at all levels, preserving at the same time the previous modelling efforts and solutions.

\section{References}

Cabeza L.F., Castellón C., Nogués M., Medrano M., Leppers R., Zubillaga O. 2007. Use of microencapsulated PCM in concrete walls for energy savings. Energy and Buildings,39 (2), 113-119.

Cao S., Gustavsen A., Uvsløkk, Jelle B.P., Gilbert J., Maunuksela J. 2010. The effect of wall integrated phase change material panels on the indoor air and wall temperature - hot 
box experiments. Proceedings of Renewable Energy Conference in Trondheim, Norway.

Castell A., Martorell I., Medrano M., Pérez G., Cabeza L.F. 2010.Experimental study of using PCM in brick constructive solutions for passive cooling. Energy and Buildings, 42 (4), 534-540.

Cerón I., Neila J., Khayet M. 2011.Experimental tile with phase change materials (PCM) for building use. Energy and Buildings, 43 (8), 1869-1874

Dutil Y., Rousse D.R., Salah N.B., Lassue S., Zalewski L. 2011. A review on phase-change materials: Mathematical modeling and simulations. Renewable and Sustainable Energy Reviews, 15 (1), 112-130

Evers A.C., Medina M.A., Fang Y. 2010. Evaluation of the thermal performance of frame walls enhanced with paraffin and hydrated salt phase change materials using a dynamic wall simulator. Building and Environment, 45 (8), 1762-1768.

Evola G., Papa N., Sicurella F., Wurtz E. 2011. Simulation of the behaviours of phase change materials for the improvement of thermal comfort in lightweight buildings. $12^{\text {th }}$ Conference of International Building Performance Simulation Association, Sydney, Australia.

Hagentoft, C-E, Sasic Kalagasidis, A., Adl-Zarrabi, B., Roels, S., Carmeliet, J., Hens, H., Grunewald, J., Funk, M., Becker, R., Shamir, D., Adan, O., Brocken, H., Kumaran, K., Djebar, R. 2004. Assessment Method of Numerical Prediction Models for Combined Heat, Air and Moisture Transfer in Building Components. Benchmarks for One-dimensional Cases. Journal of Thermal Envelope and Building Science (Journal of Building physics), 27 (4), 327-352.

Hed G. 2004. Use of phase change material for change of thermal inertia of buildings. In the proceeding of the 6th Expert Meeting and Workshop of Annex 17, Arvika, Sweden.

Heim D., Clarke J.A. 2004. Numerical modelling and thermal simulation of PCM-gypsum composites with ESP-r. Energy and Buildings, 36 (8), 795-805

Ibáñez M., Lázaro A., Belén Z., Cabeza L.F. 2005. An approach to the simulation of PCMs in building applications using TRNSYS. Applied Thermal Engineering, 25 (11-12), 1796-1807

IBPT. 2002. General report. Available from www.ibpt.org.

Johannes K., Virgone J., Kuznik F. Wang X., Haavi T., Fraisse G. 2011. Development of Sustainable Energy Storage Designs for a variety of ultra-low energy building thermal, 
phase change materials and electric storage options. Report of task $C$ of IEA Annex 23’Applying Energy Storage in Buildings of the Future’. Draft from February 24.

Karlsson, H., Sasic Kalagasidis A., Hagentoft C-E. 2005. Development of a modular toolbox in Simulink for dynamic simulations of VOC-concentration in indoor air. $9^{\text {th }} I B P S A$ conference, Montreal, Canada.

Karlsson H., 2005. Modelling of Long Wave Radiation Exchange in Enclosures with Building Integrated Heating. Proceedings of the 7th Symposium on Building Physics in the Nordic countries, Reykjavik, Iceland.

Karlsson H. 2010. Embedded water-based surface heating, Part 1: Hybrid three-dimensional numerical model. Journal of Building Physics, 33, 4, 357-392

Kontogeorgos D., Founti M. 2010. Numerical investigation of simultaneous heat and mass transfer mechanisms occurring in a gypsum board exposed to fire conditions. Applied Thermal Engineering, 30 (11-12), 1461-1469

Kosny J., Kossecka E., Brzezinski A., Tleoubaev A., Yarbrough D. 2012. Dynamic thermal performance analysis of fiber insulations containing bio-based phase change materials (PCMs). Energy and Buildings, 52,122-131

Kosny J., Yarbrough D., Miller W., Petrie T., Childs P., Syed A.M., Leuthold D. 2007. Thermal Performance of PCM-Enhanced Building Envelope Systems. Proceedings of Thermal Performance of the Exterior Envelopes of Whole Buildings, X International Conference. Clearwater beach, Florida, USA.

Kuznik F., David D., Johannes K., Roux J-J. 2011. A review of phase change materials integrated in building walls. Renewable and Sustainable Energy Reviews, 15 (1), 379391

Kuznik F., Virgone J., Johannes K. 2010. Development and validation of a new TRNSYS type for the simulation of external building walls containing PCM. Energy and Buildings,42 (7), 1004-1009.

Kuznik F., Virgone J. 2009. Experimental assessment of a phase change material for wall building use. Applied Energy, 86 (10), 2038-2046

Kuznik F., Virgone J., Noel J. 2008b. Optimization of a phase change material wallboard for building use. Applied Thermal Engineering, 28 (11-12), 1291-1298.

Kuznik F., Virgone J., Roux J-J. 2008a. Energetic efficiency of room wall containing PCM wallboard: A full-scale experimental investigation. Energy and Buildings, 40 (11-12), 148-156. 
Lin K., Zhang Y., Xu X., Di H., Yang R., Qin P. 2005. Experimental study of under-floor electric heating system with shape-stabilized PCM plate. Energy and Buildings, 37 (3), 215-220

Markets and markets. Advanced phase change material (PCM) market: Global forecast (2010 - 2015). Available from www.marketsandmarkets.com. (April2012)

Meteotest. 2009. Meteonorm, Global Meteorological Database for Engineers, Planners and Education. Version 6. Available from www.meteonorm.com. Bern, Switzerland.

Moussavi Nik, V., Sasic Kalagasidis, A., Kjellström, E.2012. Assessment of hygrothermal performance and mould growth risk in ventilated attics in respect to possible climate changes in Sweden. Building and Environment, 55 (September 2012), 96-109.

Pasupathy A., Athanasius L., Velraj R. Seeniraj R.V. 2008. Experimental investigation and numerical simulation analysis on the thermal performance of a building roof incorporating phase change material (PCM) for thermal management. Applied Thermal Engineering, 28 (5-6), 556-565

Sá A.V., Azenha M., de Sousa H., Samagaio A. 2012. Thermal enhancement of plastering mortars with Phase Change Materials: Experimental and numerical approach. Energy and Buildings, 49 (June 2012)5, 16-27

Sadineni S.B., Madala S., Boehm R.F. 2011. Passive building energy savings: A review of building envelope components. Renewable and Sustainable Energy Reviews, 15 (8), 3617-3631.

Sasic Kalagasidis, A., Weitzmann, P., Rammer Nielsen, T., Peuhkuri, R., Hagentoft, C-E, Rode, C. 2007. The International Building Physics Toolbox in Simulink. Energy and Buildings, 39, 665-674

Sasic Kalagasidis A., Karlsson, H., Hagentoft, C-E. 2005. A Simulation Tool for Temperature and Moisture Dependent Transport of VOC's in Buildings.7th Nordic Symposium on Building Physics, Reykjavik, Iceland.

Sasic Kalagasidis. A. 2004. HAM-Tools-An Integrated Simulation Tool for Heat, Air and Moisture Transfer Analyses in Building Physics. PhD thesis. Available from http://publications.lib.chalmers.se/cpl/

Schossiga P., Henninga H.-M., Gschwandera S., Haussmann T. 2005. Micro-encapsulated phase-change materials integrated into construction materials. Solar Energy Materials \& Solar Cells, 89 (2), 297-306 
Shrestha S., Miller W., Stovall T, Desjarlais A, Childs K., Porter W., Bhandari M, Coley S.2011. Modeling PCM-enhanced insulation system and benchmarking EnergyPlus against controlled field data. 12th Conference of International Building Performance Simulation Association, Sydney, Australia.

Silva T., Vicente R., Soares N., Ferreira V. 2012. Experimental testing and numerical modelling of masonry wall solution with PCM incorporation: A passive construction solution. Energy and Buildings, 49 (June 2012), 235-245

Streicher W., Cabeza L., Heinz A. Inventory of Phase Change Materials (PCM). 2005.Advanced storage concepts for solar and low energy buildings. Report of IEA Solar Heating and Cooling Programme - Task 32. Report C2 of Subtask C.

Ståhl F. Influence of thermal mass on the heating and cooling demands of a building unit. 2009. Doctoral thesis. Chalmers University of Technology. Available from http://publications.lib.chalmers.se/

Tyagi V.V., Kaushik S.C., Tyagi S.K., Akiyama T. 2011. Development of phase change materials based on microencapsulated technology for buildings: a review. Renewable and Sustainable Energy Reviews, 15 (2), 1373-1391

Voelker C., Kornadt O., Ostry M. 2008. Temperature reduction due to the application of phase change materials. Energy and Buildings, 40 (5), 937-944

Woloszyn M., Rode C Modelling Principles and Common Exercises. IEA Annex 41, MOISTENG. Final report of Subtask 1. 


\section{Appendix - Additional details of the numerical experiments from section 3.3}

Thermal properties of the building materials in the test room, as provided in Kuznik and Virgone (2009), are summarized in Table 6. The apparent volumetric heat capacity and thermal conductivity of the PCM are shown in the graph within the same table (from Kuznik et al., 2008a). In conformity with the explanations provided with the experiment, solar absorptivity and global emissivity of opaque surfaces in the room are 0.67 and 0.95 respectively. These properties of the glass wall are not provided, hence assumed as 0.05 and 0.95, and solar transmittance 0.87 .

Table 6 Thermal properties of the building materials in the test room

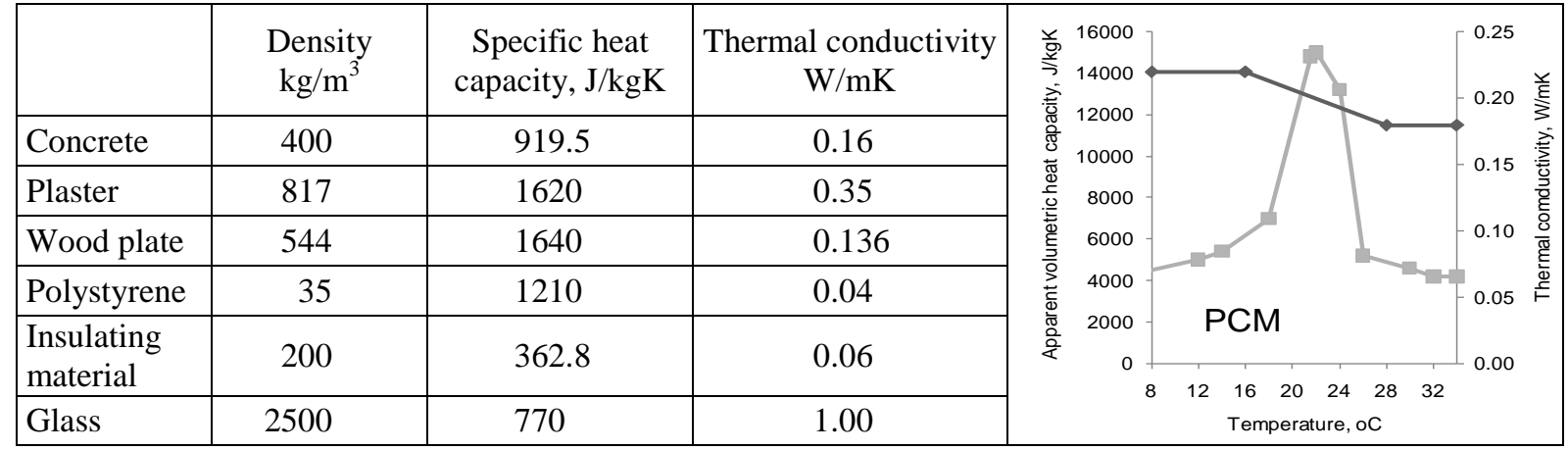

Long-wave radiation heat exchange between the surfaces in the zone is modelled by so called 'star model', where the star represents a fictitious node whose temperature is found as area weighted mean temperature of all the surfaces in the zone. The net long-wave radiation that reaches a surface is then found from a difference between the temperature of the star and the air temperature, multiplied by a constant radiative surface transfer coefficient, $5 \mathrm{~W} / \mathrm{m}^{2} \mathrm{~K}$. In this way, all surfaces in the zone absorb the same amount of net long-wave radiation. The net radiation from other radiative sources, i.e. from the solar simulator, through the glazed wall, is also area weighted and then passed to all interior surfaces. The convective surface heat transfer coefficient is set to a constant value, $3 \mathrm{~W} / \mathrm{m}^{2} \mathrm{~K}$. Due to these assumptions, the calculated surface temperatures of the north and west wall are almost the same, as it is shown 
in Figure 15. Since the measurements show clear differences between the temperatures of the north and the west wall, the whole numerical experiment has been recalculated with a more detailed model for the long wave radiation, which is presented in Karlsson (2005).
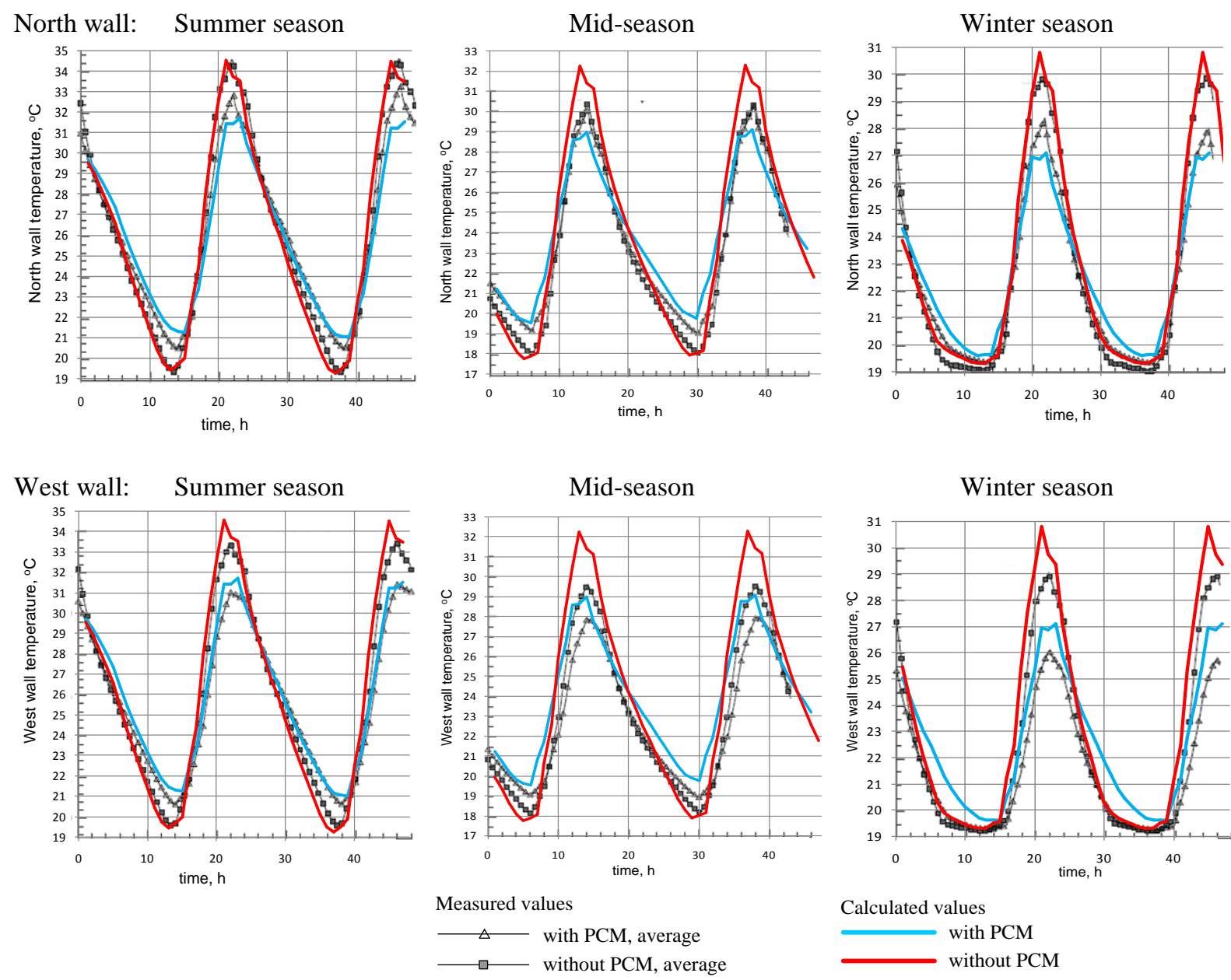

Figure 15 Measured and calculated temperatures at the interior surface of the north and west walls, for different season

In this model, the long-wave radiation exchange between the surfaces in the room is based on exact view factors and on the actual temperatures of the surfaces. In this way, the apparent surface radiative heat transfer coefficient for a surface varies. The numerical model shows clear differences between the temperatures of the west and north wall, as it is shown in Figure 16. A very good agreement is achieved between the measured and the calculated temperatures for the most of the cases. For example, the air temperature inside the room 
during the mid-season is closer to the measured values with the refined model for the longwave radiation than what has been obtained with a simpler model (see Figure 12). However, a larger discrepancy can be observed for the same season, at the walls in the room without PCM. The model shows larger temperature amplitudes than what has been indicated with the measurements. This is somewhat unexpected result, since the same model shows better agreement with the measurements in all other cases. An observation can be made in regard to the measurements for this particular season - the maximum temperatures of the north wall with and without PCM are the same, while in all other cases they differ for about $1-3{ }^{\circ} \mathrm{C}$. The authors of the experiment, Kuznik and Virgone (2010), comment in the text that a decrease of the temperature amplitude for the north wall with PCM is $1.3{ }^{\circ} \mathrm{C}$. However, this difference cannot be found in the graphical presentation of the results (see for example Figure 16). Therefore, further investigations about this particular case have not been conducted.

Together with the more detailed model for long-wave radiation in the room, the distribution of solar radiation in the room has been changed from the area weighted values, as used in the simple model, to the fractions assigned to each surface: $50 \%$ to the floor, $20 \%$ to the north wall, while the west and east wall and the ceiling each get $10 \%$. These fractions are estimated from the position of the lamps in the solar simulator (see Kuznik and Virgone, 2010). The selected values give also the best match with the measurements. Even here, the convective surface heat transfer coefficient is set to a constant value, $3 \mathrm{~W} / \mathrm{m}^{2} \mathrm{~K}$.

The final example refers to the winter case and to the apparent set point temperature of $19{ }^{\circ} \mathrm{C}$. When the same value is used in numerical simulations, lower minimum air temperatures in the room are calculated, as shown in Figure 17.Thus, the model is sensitive to the set point temperature. The apparent set point temperature of $19{ }^{\circ} \mathrm{C}$ could be a consequence of a low response of the heater. In the simulations, a heater of power $1500 \mathrm{~W}$ and with $\mathrm{P}$ 
controller, where $\mathrm{P}=500$, is used. In addition, $40 \%$ of the nominal heating power is

transferred by heat convection and the rest by radiation. Note however that all these details are just assumptions. Only the heating power of the heater is provided in the original reference.

Summer season: air temperature

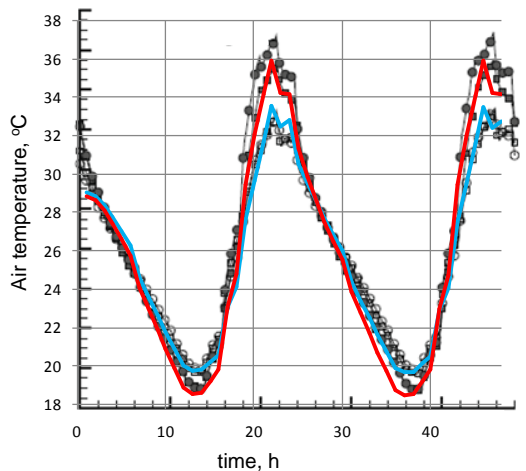

Mid-season: air temperature

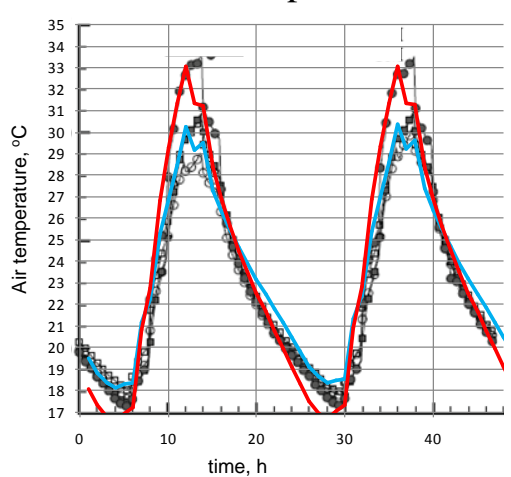

Winter season: air temperature

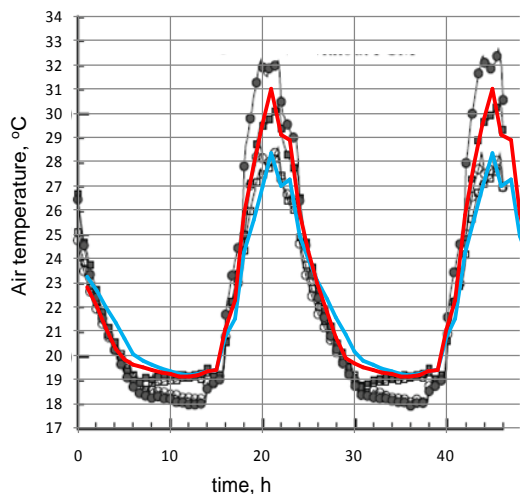

Measured values

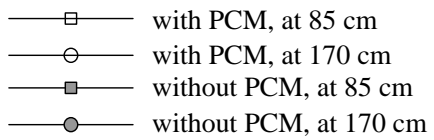

North wall

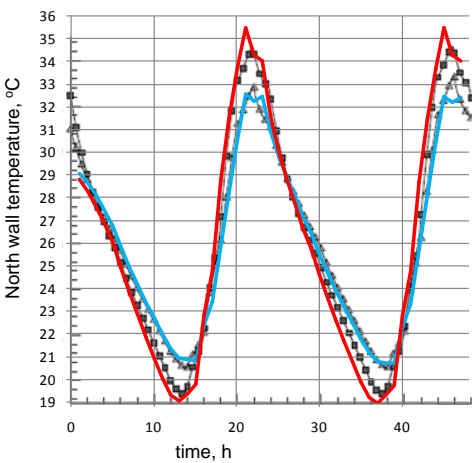

North wall

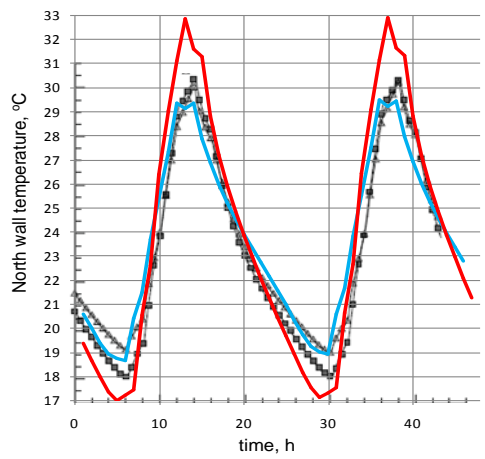

North wall

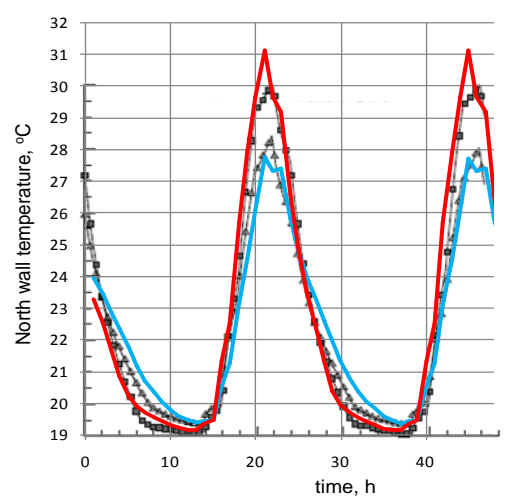

Measured values

$\triangle$ with PCM, average

$\longrightarrow$ without PCM, average
West wall

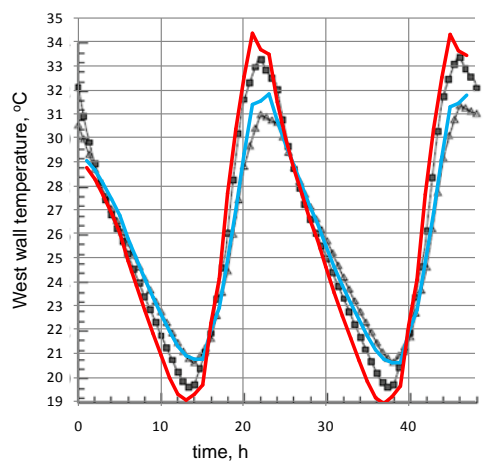

West wall

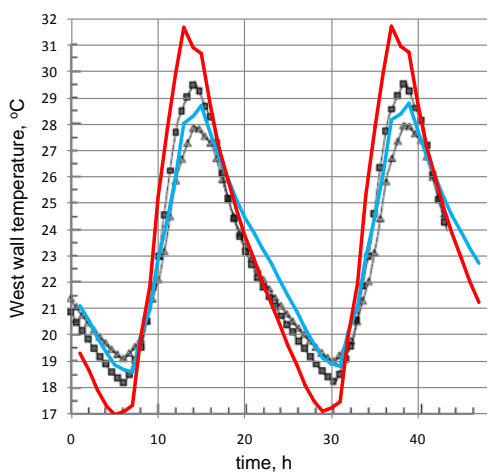

West wall

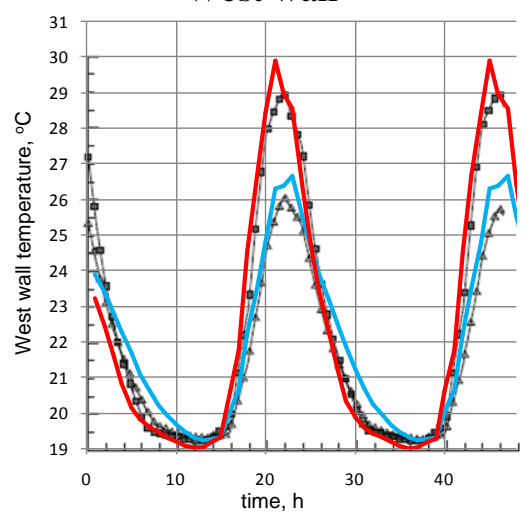

Calculated values

with PCM

Figure 16 Measured and calculated temperatures (with the detailed radiation model) of the air and at the interior surfaces of the north and west wall, in the winter season 

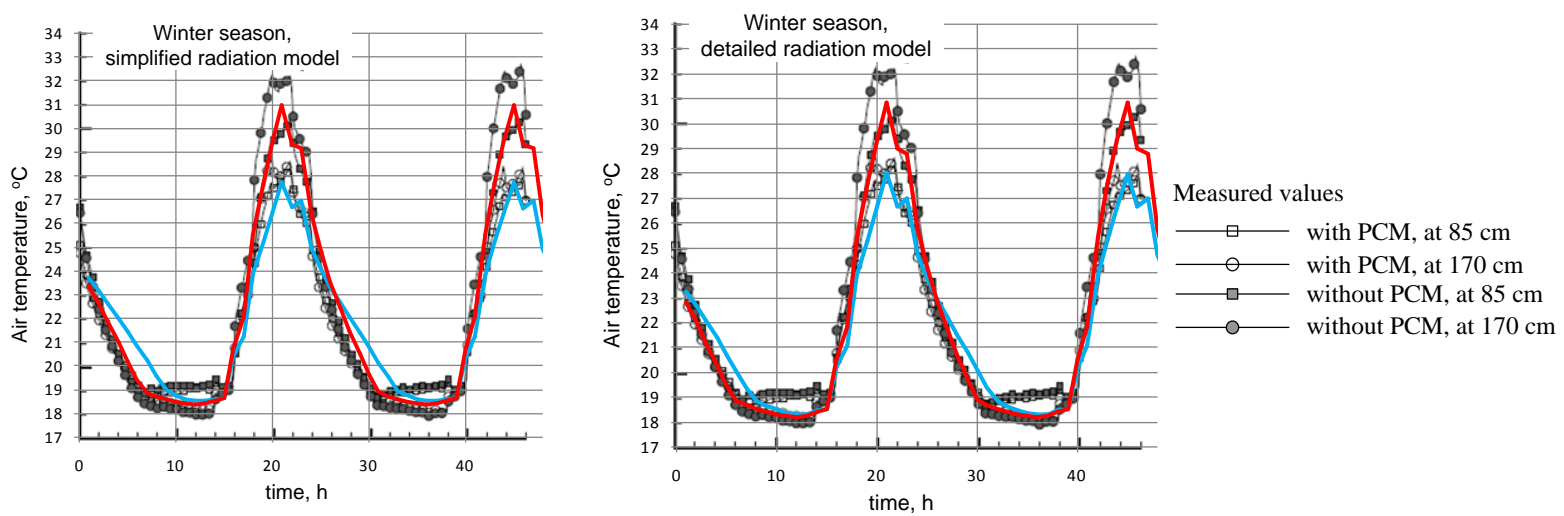

Figure 17 Measured and calculated temperatures of the air in the winter season. Set point temperature for heating is $19{ }^{\circ} \mathrm{C}$. Simplified and detailed radiation model. 